\title{
ENERGY STORAGE PLANNING IN DISTRIBUTION SYSTEMS CONSIDERING LIFE-CYCLING-USAGE RELATIONSHIP
}

by

\author{
Nastaran Hajia \\ Bachelor of Science \\ Sharif University of Technology, Tehran, Iran, 2013
}

\begin{abstract}
A thesis presented to Ryerson University
in partial fulfillment of the

requirements for the degree of

Master of Applied Science

in the program of

Electrical and Computer Engineering
\end{abstract}

Toronto, Ontario, Canada, 2015

(C) Nastaran Hajia 2015 


\section{AUTHOR DECLARATION}

I hereby declare that I am the sole author of this thesis. This is a true copy of the thesis, including any required final revisions, as accepted by my examiners.

I authorize Ryerson University to lend this thesis to other institutions or individuals for the purpose of scholarly research.

I further authorize Ryerson University to reproduce this thesis by photocopying or by other means, in total or in part, at the request of other institutions or individuals for the purpose of scholarly research.

I understand that my thesis may be made electronically available to the public. 


\title{
ENERGY STORAGE PLANNING IN DISTRIBUTION SYSTEMS CONSIDERING LIFE-CYCLING-USAGE RELATIONSHIP
}

\author{
Nastaran Hajia \\ Master of Applied Science \\ Electrical and Computer Engineering \\ Ryerson University
}

2015

\begin{abstract}
Asset expansion planning in Distribution System is important and should be expanded to consider utility scale energy storage systems such as batteries, flywheels, compressed air, thermal, etc. Battery Energy Storage Systems (BESS) are maturing for utility scale applications and are considered in this thesis for asset planning exercise.

Unlike other electromechanical assets such as generators, transformers, motors, feeders, distribution lines, etc., usage parameters such as number of storage cycles and depth of discharge have a dramatic nonlinear effect on the life of Battery Energy Storage Systems. Hence, in the optimal asset planning formulation of electric power distribution systems considering BESS, it is imperative to include their relationship between life in years, number of storage cycles and extent of usage in terms of depth of discharge.

A new optimal asset expansion planning formulation and algorithm for distribution systems is developed and presented in this thesis that considers (1) new sources of energy supply, and (2) BESS, while modeling nonlinear relationship life-cycling-usage of BESS.

The formulation aims to minimize annualized cost of the optimal expansion plan while satisfying forecasted demand and other distribution system service requirements. The proposed method in this thesis is then used to develop optimal expansion plans for a 6bus synthetic system and an IEEE 33-bus distribution network. The results show the effect of considering the life-cycling-usage relationship of BESS on optimal asset expansion plans.

Further, using sensitivity analysis, the effect of ratio off-peak load to peak load on total asset costs are analyzed and reported.
\end{abstract}




\section{ACKNOWLEDGMENTS}

First and foremost I would like to express my deepest gratitude toward my supervisor, Professor Bala Venkatesh, for his continuous guidance, encouragement and support throughout my Masters and providing me with an inspiring research environment.

I would like to extend my very special thanks to all my professors and colleagues in Ryerson University for guiding me along the way and for their tireless and patient teachings.

Many thanks to Dr. Reza Ghaffari and my dear friend Mazhar Moshirvaziri who helped me in editing this thesis. I wish them best of luck in all of their future endeavors.

I would like to thank Dr. Peng Yu and everyone else in the Power and Energy Analysis Laboratory who have helped me and taught me many things during the two years of my education at Ryerson University.

Last but not least, I would like to thank my dearest parents, brother and sister for their constant encouragement and well wishes even though they are far from me. 


\section{Table of Contents}

AUTHOR DECLARATION ....................................................................................... ii

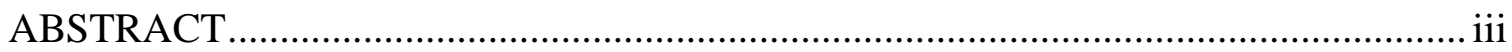

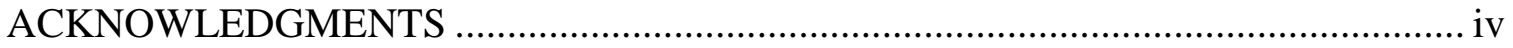

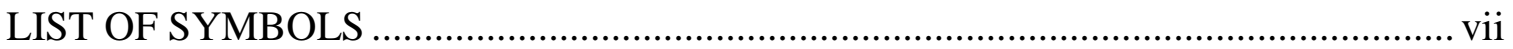

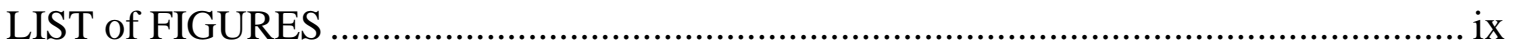

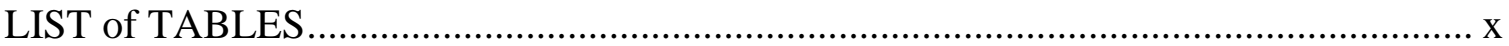

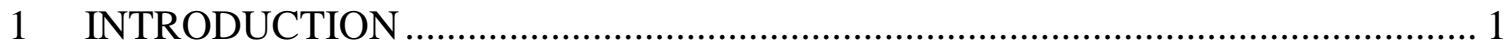

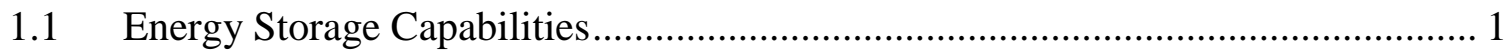

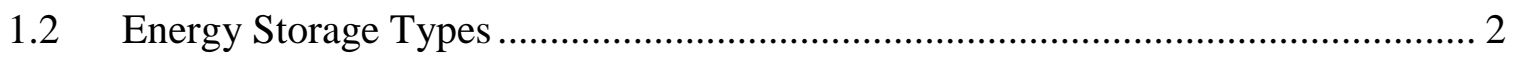

1.2.1 Mechanical storage devices ........................................................... 3

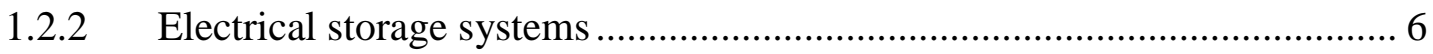

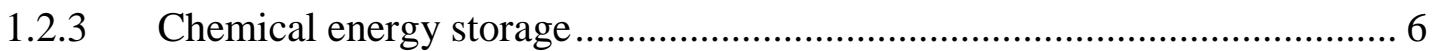

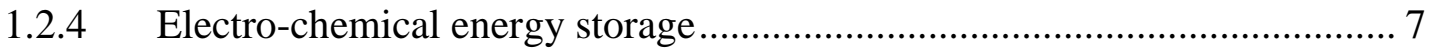

1.3 Energy Storage Applications in Power Systems ................................................ 10

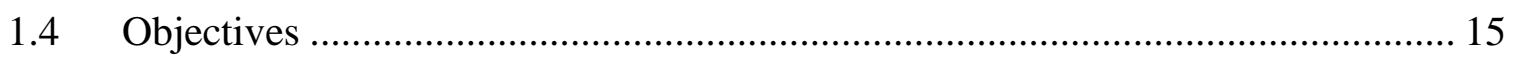

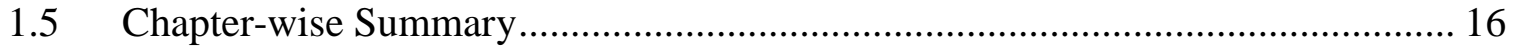

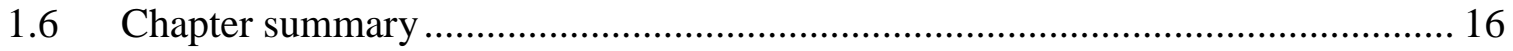

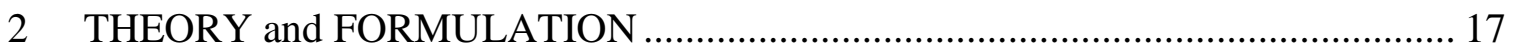

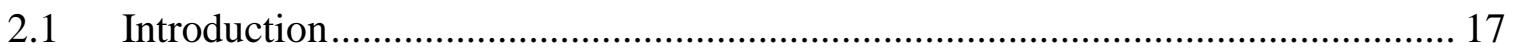

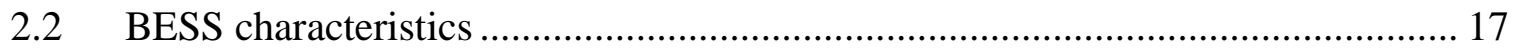

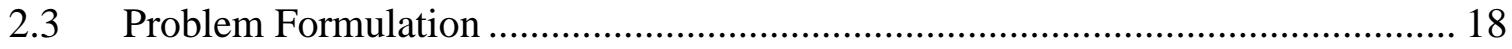

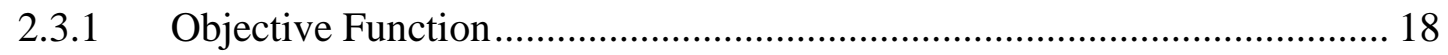

2.3.2 Constraints ................................................................................ 19

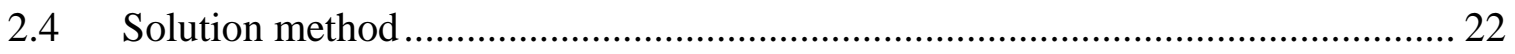




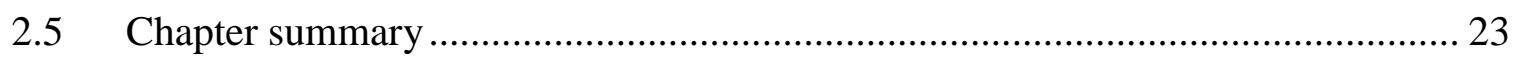

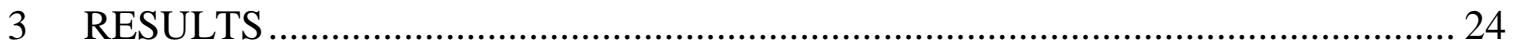

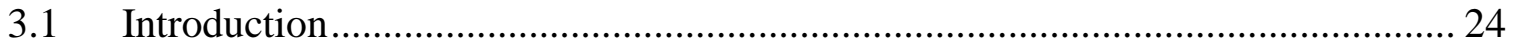

3.2 Test System 1: 6 Bus Synthetic System.......................................................... 24

3.3 Test System 1 (6-Bus) Sensitivity Analysis.............................................................. 32

3.4 Test System 2: 33-Bus System ……………………........................................ 33

3.5 Test System 2 (33-Bus) Sensitivity Analysis...................................................... 38

3.6 Effect of Life-Cycle-Usage Characteristics ……………………......................... 39

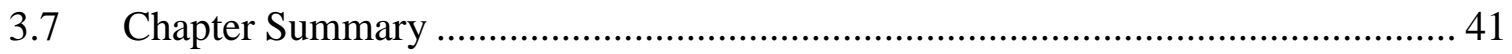

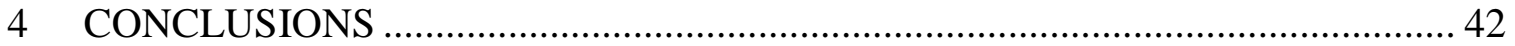

4.1 Summary and contribution........................................................................... 42

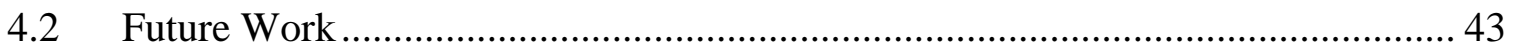

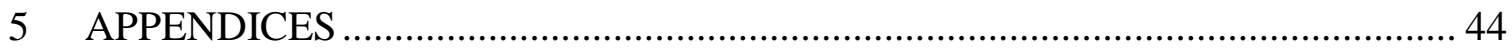

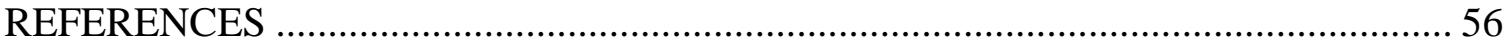




\section{LIST OF SYMBOLS}

$l, \mathrm{i}, \mathrm{k}, \mathrm{h}$

$P G_{i h}$

$Q G_{i h}$

$S G_{i h}$

$\overline{P G_{l}}$

$P D_{i h}, Q D_{i h}$

$S D_{i h}$

$S T_{i h}$

$P T_{i h}, Q T_{i h}$

$S L_{i h}$

$\overline{S L_{l}}$

$V_{i h} \angle \delta_{i h}$

$V_{h}$

$\bar{V}_{i}, \underline{V_{i}}$

$y_{l}$

$P E_{k h}$

$E E_{k h}$
Indices for line, bus, BESS unit and time zone

real power of generation

reactive power of generation

Apparent power of the generation

Maximum generator power capacity

real and reactive power load

Apparent power of load

Net apparent power injected from the $i^{\text {th }}$ bus into connected transmission lines

Net real and reactive power injected from $\mathrm{i}^{\text {th }}$ bus into connected transmission lines

Power flow in line I at hour $\mathrm{h}$

Maximum line power flow Capacity

Bus voltage phasor

Vector of bus voltage phasors for time zone $h$

lower and upper limits on the $i^{\text {th }}$ bus voltage magnitude

Admittance of line $l$

Real power of BESS

Energy of BESS 


\begin{tabular}{|c|c|}
\hline$\overline{P E_{l}}$ & Maximum BESS power capacity \\
\hline$\overline{E E_{l}}$ & Maximum BESS energy capacity \\
\hline EConst & Product of NC, NY and DOD, a constant \\
\hline$C G$ & Annualized cost coefficient for generators \\
\hline$C E E$ & BESS energy coefficient - capital cost \\
\hline CEP & BESS power coefficient - capital cost \\
\hline$\alpha$ & Self-discharge efficiency \\
\hline$N B$ & Number of buses \\
\hline$N E$ & Number of BESS units \\
\hline NC & BESS number of cycles per day \\
\hline$N Y$ & BESS life in number of years \\
\hline NH & Number of time zones \\
\hline \multirow[t]{2}{*}{ NG } & Number of Generators \\
\hline & ABBREVIATIONS AND ACRONYMS \\
\hline BESS & Battery Energy Storage System \\
\hline$O P F$ & Optimal Power Flow \\
\hline SOC & State of Charge \\
\hline$D O D$ & Depth of Discharge \\
\hline$C D M$ & Conservation and Demand Management \\
\hline
\end{tabular}




\section{LIST OF FIGURES}

Figure 1-1 Compressed Air Energy Storage (CAES) with underground reservoir [9]...... 4

Figure 1-2 Flywheel Energy Storage (FES) [9] ....................................................... 5

Figure 1-3 Pumped Hydro Energy Storage (PHES) [9].............................................. 6

Figure 1-4 Schematic of a Battery Energy Storage System (BESS) [9] .......................... 8

Figure 1-5 Principals of a Lithium-ion battery [9] ..................................................... 9

Figure 2-1 BESS relationship between life in number of years with usage in terms of

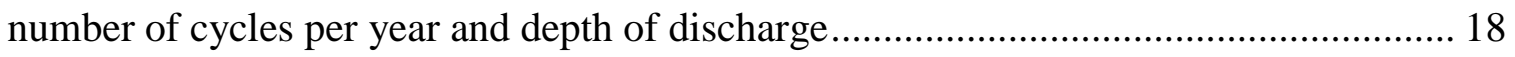

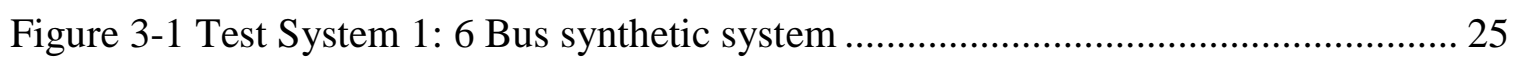

Figure 3-2 Real power loads at each bus in every time zone..................................... 26

Figure 3-3 Reactive power loads at each bus in every time zone ................................. 26

Figure 3-4 Generated real and reactive power in each of the three time zones .............. 29

Figure 3-5 BESS real power and energy at the beginning of the time zones for the 6 bus

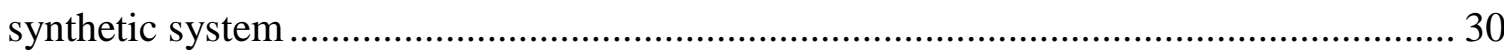

Figure 3-6 Generated power with and without BESS in the 6-bus distribution system ... 31

Figure 3-7 BESS and Generator size for different ratio of off-peak to peak load .......... 32

Figure 3-8 Real power load profile for the 33 bus system in each time zone.................. 33

Figure 3-9 Reactive power load profile for the 33-bus system in each time zone........... 34

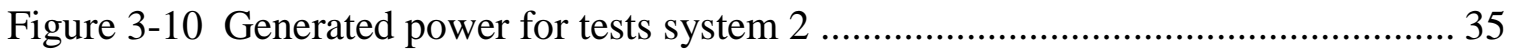

Figure 3-11 BESS power for test system 2 (33-bus) in each of the three time zones ..... 36

Figure 3-12 BESS energy at the beginning of each time zone for test system 2 ........... 36

Figure 3-13 Generated power with and without BESS in the 33 bus distribution system 37

Figure 3-14 BESS and Generator size for different ratio of off-peak to peak load ......... 39

Figure 3-15 Energy Capacity vs. energy cost in 6-bus system .................................... 40 


\section{LIST OF TABLES}

Table 1-1 Specific energy for different battery chemistry ........................................... 8

Table 1-2 Characteristics of a Li-ion BESS $\left(\mathrm{LiFePO}_{4}\right)$ [18] ...................................... 9

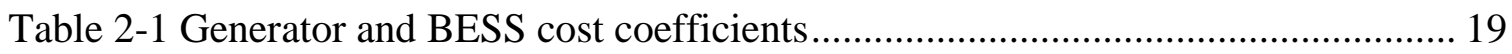

Table 3-1 Generator and BESS energy in each of the three time zones ......................... 27

Table 3-2 BESS Characteristics for the 6 bus system................................................... 28

Table 3-3 voltage magnitude and phase angle in each of the three time zone for the 6 bus

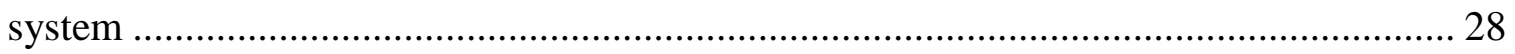

Table 3-4 System cost with and without the use of a BESS for the test system 1.......... 30

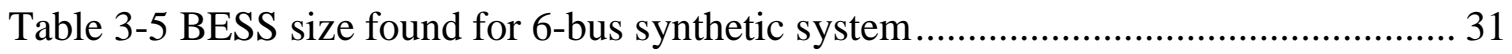

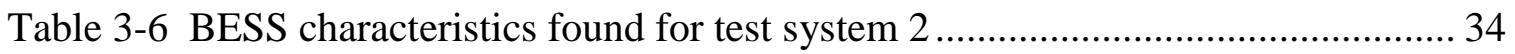

Table 3-7 Generator power and BESS power and energy found for the 33 bus test system

Table 3-8 System cost with and without the use of a BESS for the 33 bus system....... 38

Table 3-9 BESS size found for the 33-bus System.................................................. 38

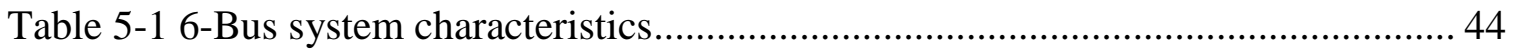

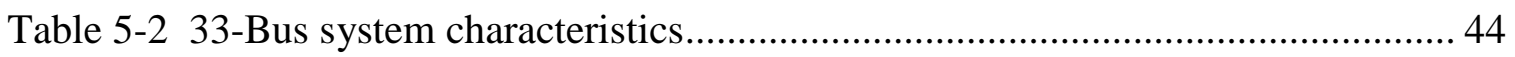

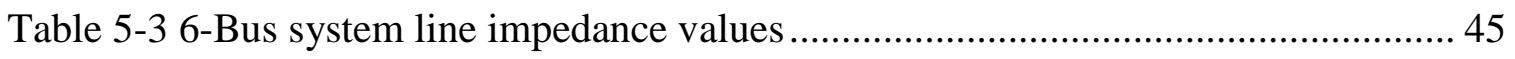

Table 5-4 6-Bus system real power load values .................................................... 45

Table 5-5 33-Bus system reactive power load values in each time zone........................ 46

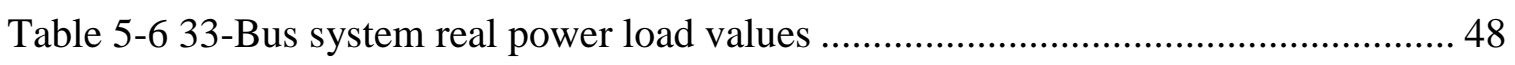

Table 5-7 33-bus system resulting voltage magnitude at each bus in each time zone..... 50

Table 5-8 33-Bus system resulting voltage phasor at each bus in each time zone .......... 52

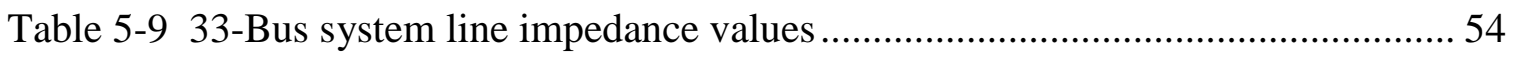




\section{CHAPTER 1}

\section{INTRODUCTION}

Asset planning in distribution systems is to determine the best expansion plan that costs the least while providing adequate quality of service and satisfying the demand of connected loads. Optimal asset expansion plans should be cognizant of several new elements connected to distribution systems such as renewables (wind and solar), electric cars, smart meters, CDM (conservation and demand management) solutions, etc. Importantly, utility scale energy storage is now commercially viable and utilities could include them in the optimal asset expansion plan where appropriate. Battery Energy Storage Systems, BESS, are particularly of interest as they can help manage flow of energy by storing energy when demand is low and consequently the driving energy prices are low and releasing it when demand is high and driving energy prices are high. After all, optimal distribution system asset planning strategy is to deliver energy to customers with the minimum cost at the service quality required by prevalent standards.

BESS holds a potential for utility distribution system applications. These include load leveling, distribution system asset cost deferral, CDM, volt-var control, etc. An aspect of BESS that is uniquely different in contrast with other regular distribution system assets is that usage, cycling and life are closely interlinked and their relationship is highly nonlinear. Hence, a careful consideration of BESS characteristics must be included in distribution system asset expansion planning exercise.

\subsection{Energy Storage Capabilities}

Increasing electricity demand and resulting pollution has lead energy policy makers and researchers to consider alternative energy resources such as solar and wind. Especially after the energy crisis of the 1970s, more and more studies have been conducted in this area and researchers are looking for ways to increase the renewable energy generation in an economically beneficial way [1]. 


\section{INTRODUCTION CHAPTER 1}

Other factors contributing to the increased interest in renewable energy include increased energy prices, the negative environmental impact of fossil fuel electricity generation and climate change. Fossil fuel electricity generation accounts for more than $40 \%$ of global $\mathrm{CO} 2$ emissions and this makes it one of the major issues in the energy sector $[2,3]$.

As an example for renewable energy, wind power, is a suitable alternative for fossil fuel generated electricity for some geological areas and yet, its intermittent nature can provide some problems for the power system, specifically when we are interested in high penetration of wind power [4]. Energy storage systems can help with the ramp control and frequency control of wind turbines. Therefore, if appropriate and affordable energy storage was at hand, the development of renewable energy would be going forward at a much faster pace $[5,6]$.

Energy Storage systems are very useful as they can store energy when it is in excess and release when it is in short supply. With increased research and development, energy storage systems are becoming cost competitive. Moreover, it has been predicted that worldwide electricity demand will double by 2050. In short, energy storage devices would be beneficial in terms of both economic value and environmental benefits in distribution system applications [7].

\subsection{Energy Storage Types}

Energy Storage Systems (ESS) can be installed in the power grid in many different capacities. In order to explore how ESS can benefit the power grid in terms of reliability and economic savings, it is necessary to study the characteristics of ESS in depth [8]. Some of the energy storage system applications considering both transmission and distribution sectors are [9]:

- electric energy time shift or energy arbitrage,

- frequency regulation, 


\section{INTRODUCTION CHAPTER 1}

- spinning, non-spinning, and supplemental reserves,

- voltage and reactive power support,

- black start,

- transmission upgrade deferral,

- transmission congestion relief,

- distribution upgrade deferral,

- power quality improvement,

- power reliability improvement,

- retail energy time-shift, and

- demand charge management.

There are four general types of energy storage systems commonly used for large-scale applications, mechanical, electrical, chemical, and electrochemical [10]. In the next section, we will briefly cover some of the most commonly used forms of energy storage systems.

\subsubsection{Mechanical storage devices}

In this form of energy storage system, energy is stored in mechanical system in the form of potential or kinetic energy. Compressed air, pumped hydro and flywheel systems are among the most important solutions in this category and have prevalent application for bulk electric power systems.

\subsubsection{Compressed Air Energy Storage (CAES)}

In this mechanical energy storage system, off-peak electrical power is used to compress air and store it in large storage reservoirs such as salt caverns, large balloons submerged in water, steel tanks, etc. This energy storage mechanism is highly dependent on site geology and the process is not $100 \%$ pollutant free. Adiabatic compressed air energy storage is also used where heat from compressed air is recovered in order to aid in the energy storage process and improve efficiency of the energy storage system. A schematic of this type of energy storage system is shown in Figure 1-1. 


\section{INTRODUCTION CHAPTER 1}

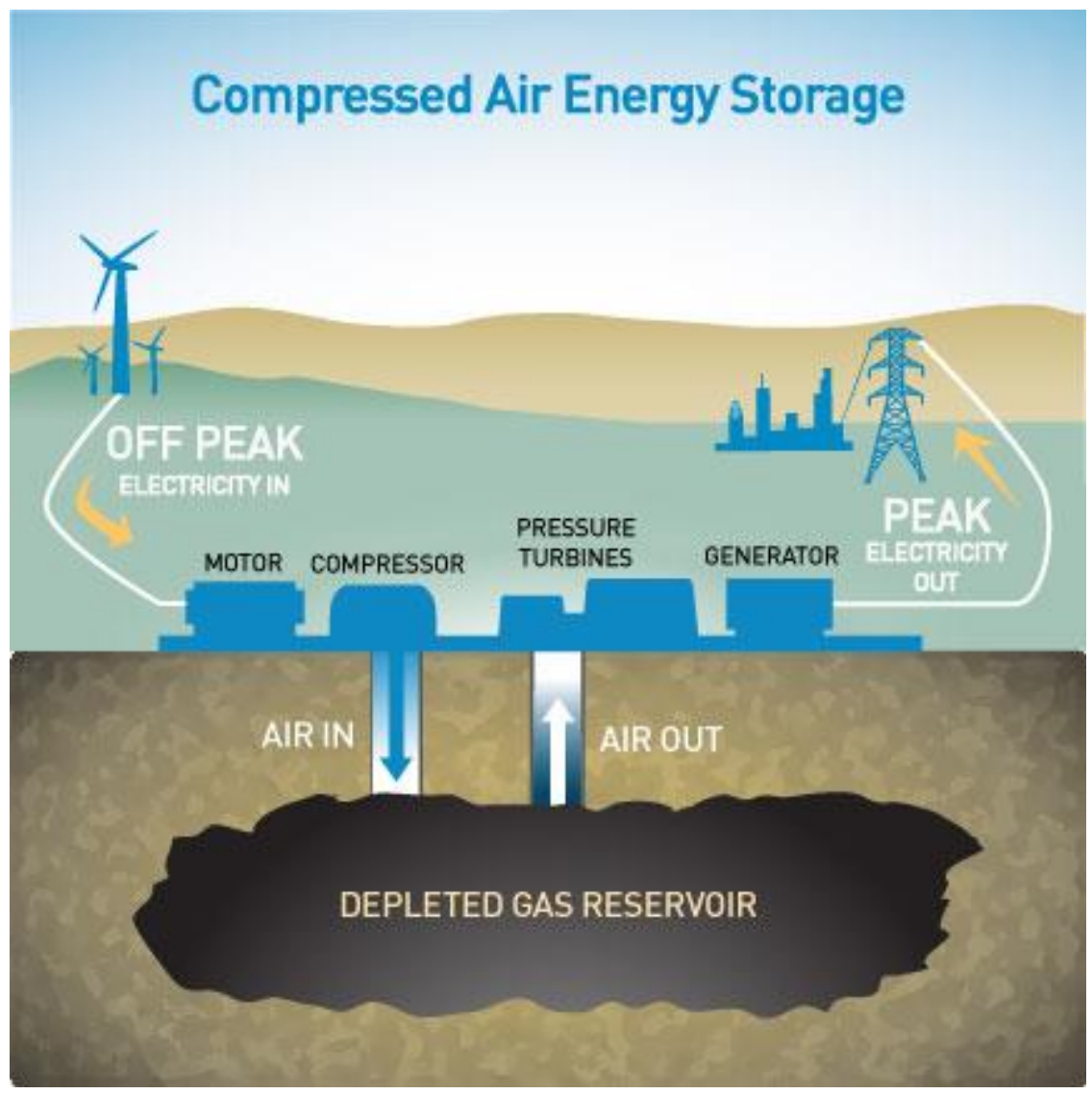

Figure 1-1 Compressed Air Energy Storage (CAES) with underground reservoir [9]

\subsubsection{Flywheel Energy Storage (FES)}

Electricity is used to accelerate the rotor and therefore stored as kinetic energy (Figure 1-2). As a result, charging time can be fast and the state of charge doesn't affect the efficiency. Such characteristics on top of low maintenance cost, long life cycle, high efficiency, being environmentally friendly, wide operating temperature range and ability to survive in harsh conditions make FES suitable for many applications. However, idling losses are high which means the FES systems are often neglected in favor of other more efficient energy storage devices in applications where long storage duration is required. FES systems are usually used for short storage duration such as power regulation, frequency regulation, ramping, etc. where a burst of energy is required. 
INTRODUCTION CHAPTER 1

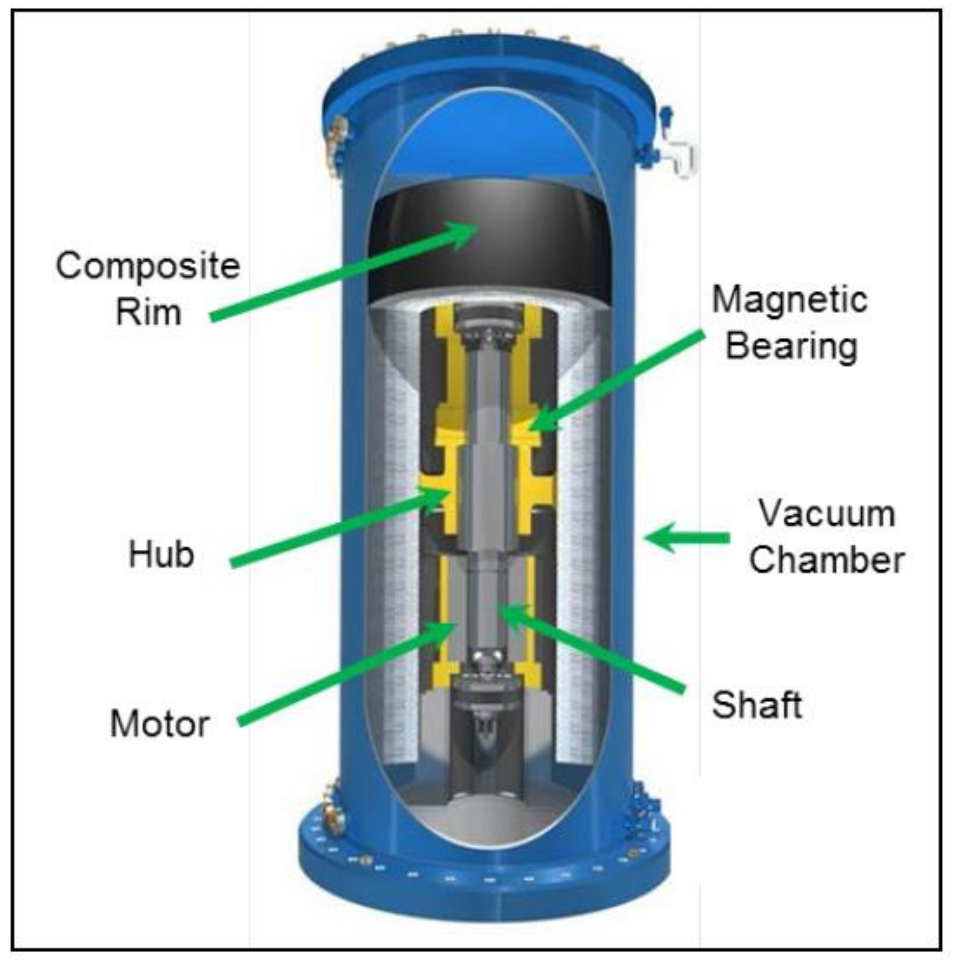

Figure 1-2 Flywheel Energy Storage (FES) [9]

\subsubsection{Pumped Hydro Energy Storage (PHES)}

In this mechanical storage system, electricity is used to pump water to an up-hill storage location during hours when electricity demand is low thereby storing energy as potential energy. When the water is released down-hill, it will be used to produce electricity by driving a generator that might be used during hours with high electricity demand. Although this type of energy storage has the potential to have very large capacity, its usage is very limited due to large capital cost and geographical restrictions. Figure 1-3 shows an illustration of this type of mechanical energy storage system. 
INTRODUCTION CHAPTER 1

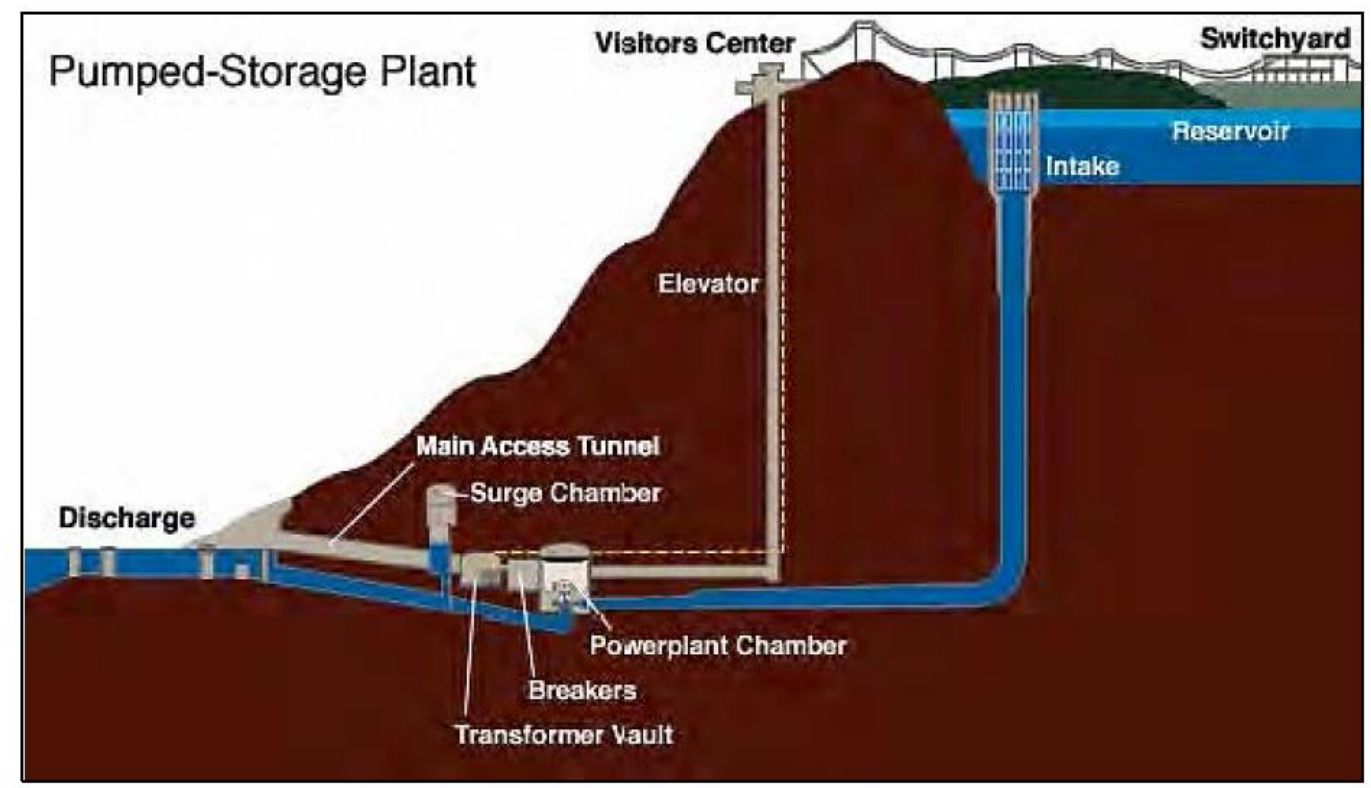

Figure 1-3 Pumped Hydro Energy Storage (PHES) [9]

\subsubsection{Electrical storage systems}

The main energy storage systems in this category of storage devices store energy in a magnetic field which will be released upon need. A prime example of this technology is Superconductive-Magnetic Energy Storage (SMES). In this technology, a superconducting coil is first cooled to below its superconducting critical temperature and then the energy is stored in a lossless fashion in the form of magnetic energy. SMES have high round trip energy efficiency as well as fast dynamic response [11]. High cost of super conducting wire as well as special requirements for cryogenic cooling, limit the usage of this technology to short-term energy storage purposes such as UPS [12, 13].

\subsubsection{Chemical energy storage}

Chemical Energy storage devices have become popular in recent years mainly for their ability to perform without having significant green-house emissions and very high storage capacity. An example of chemical energy storage systems is Hydrogen energy 


\section{INTRODUCTION CHAPTER 1}

storage. One problem hindering the application of this type of energy storage is its low round trip efficiency.

\subsubsection{Electro-chemical energy storage}

A well-known storage mechanism for electric energy is in the form of electrochemical storage system and almost everyone have seen and used this type of storage devices in their lifetime. Batteries and super-capacitors are the most common form of this category. Innumerable types of battery technologies are available and used with features that suit certain applications. Whilst some are more suitable than others, the following literature discusses most popular technologies with grid scale utility applications considering bulk energy storage capability.

\subsubsection{Battery Energy Storage System (BESS)}

BESS are usually chosen for their special features including being environmentally friendly during operation, high efficiency, high energy density, small foot print, long life-cycle, low maintenance, etc. [14, 15]. Also, because of their often small size, they are easier to relocate and thus suitable for distribution systems and also for the purpose of integrating renewable energy. Common types of batteries include: Sodium-Sulfur, Sodium-Nickel-Chloride, Vanadium-Redox, Iron-Chromium, ZincBromine, Zinc-air, Lead-Acid and Lithium-ion. Among these types, Li-ion batteries have characteristics such as relatively higher energy density, very slow self-discharge, long life-cycle and high efficiency which are the reasons many consider them to be promising among the other battery types $[16,17]$. Figure 1-4 shows a schematic of a typical BESS and Figure 1-5 shows the internal structure of a Lithium-ion battery. A comparison between specific energy of different battery types is presented in

Table 1-1 [18] and Table 1-2 shows the characteristics of a Lithium-ion BESS $\left(\mathrm{LiFePO}_{4}\right)$. 


\section{INTRODUCTION CHAPTER 1}

Table 1-1 Specific energy for different battery chemistry

\begin{tabular}{|l|c|c|c|c|c|c|c|}
\hline & $\begin{array}{c}\text { Lead- } \\
\text { Acid }\end{array}$ & $\begin{array}{c}\text { Ni- } \\
\mathrm{Cd}\end{array}$ & $\begin{array}{c}\mathrm{Ni}- \\
\mathrm{MH}\end{array}$ & $\begin{array}{c}\mathrm{Li}- \\
\text { Phosphate }\end{array}$ & $\begin{array}{c}\text { Li-MN } \\
\text { Oxide }\end{array}$ & $\begin{array}{c}\text { Li-Ni-Mn } \\
\text { Co Oxide }\end{array}$ & $\begin{array}{c}\text { Li-Co } \\
\text { Oxide }\end{array}$ \\
\hline $\begin{array}{l}\text { Typical Specific } \\
\text { Energy (Wh/kg) }\end{array}$ & 40 & 60 & 90 & 110 & 120 & 140 & 170 \\
\hline
\end{tabular}

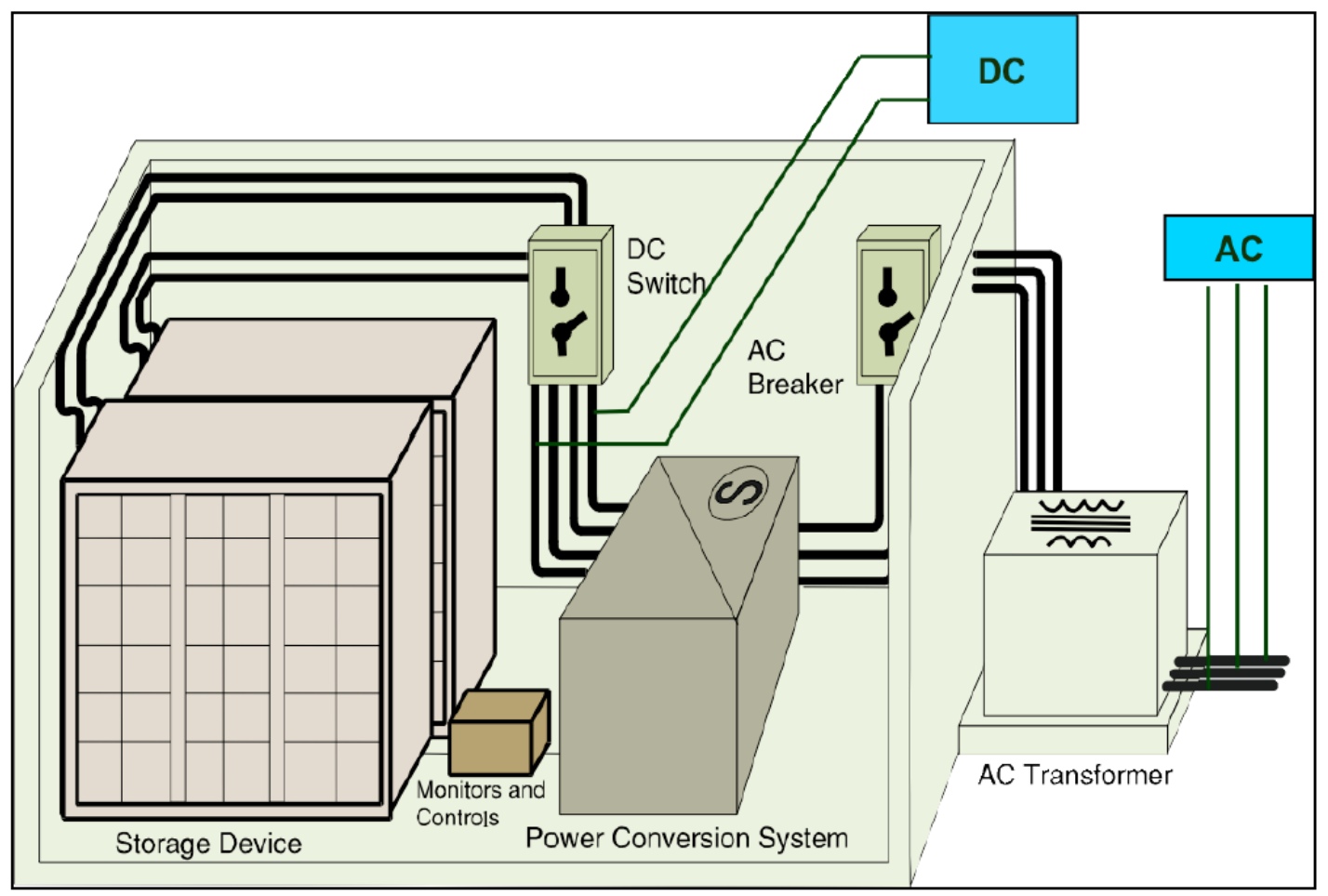

Figure 1-4 Schematic of a Battery Energy Storage System (BESS) [9] 


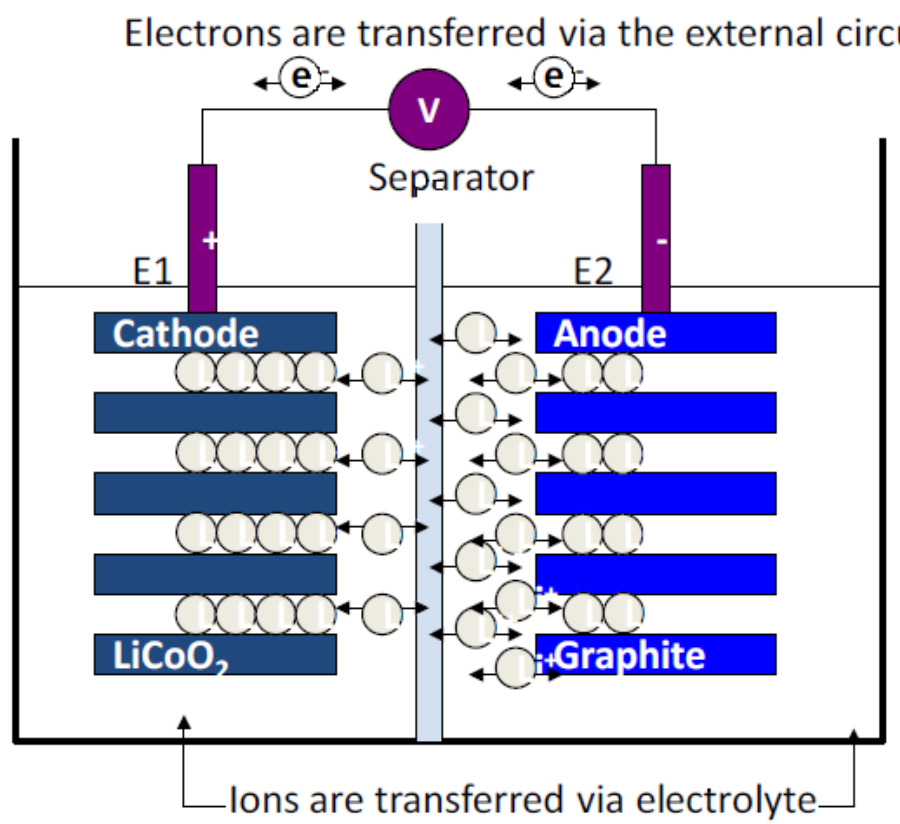

Figure 1-5 Lithium-ion battery internal structure [9]

Table 1-2 Characteristics of a Li-ion BESS $\left(\mathrm{LiFePO}_{4}\right)$ [18]

\begin{tabular}{|l|l|}
\hline \multicolumn{2}{|c|}{ Lithium-Iron-Phosphate } \\
\hline Nominal Voltage (V) & $3.2-3.3$ \\
\hline $\begin{array}{l}\text { Specific Energy } \\
\text { (Capacity) (Wh/Kg) }\end{array}$ & $90-120$ \\
\hline Charge (C-rate) & $1 \mathrm{C}$ typical, charges to 3.65V; 3h charge time typical \\
\hline Discharge (C-rate) & $\begin{array}{l}1 \mathrm{C}, 25 \mathrm{C} \text { on some cells; 40A pulse (2s); } 2.5 \text { volt cut-off } \\
\text { (lower than 2 V causes damage) }\end{array}$ \\
\hline Cycle life & $1000-2000$ \\
\hline Thermal runaway & $270^{\circ} \mathrm{C} ;$ Very safe even at 100\% SOC \\
\hline Applications & $\begin{array}{l}\text { Portable and stationary needing high load currents and } \\
\text { endurance }\end{array}$ \\
\hline Specifics & $\begin{array}{l}\text { Flat voltage discharge curve but low capacity } \\
\text { One of safest Li-ions } \\
\text { Elevated self-discharge }\end{array}$ \\
\hline
\end{tabular}




\section{INTRODUCTION CHAPTER 1}

\subsubsection{Super-Capacitor Energy Storage (SCES)}

In this type of storage device, energy is stored between a pair of charged plates as in a capacitor. A benefit of SCES is that they can be repeatedly charged and discharged without any effect on their efficiency within guaranteed life. Also, high efficiency and long life-cycle have further paved the way for the utilization of this technology [19]. SCES have a very high power and low energy capacity. They are typically suited for fast charging and discharging applications.

\subsection{Energy Storage Applications in Power Systems}

Many researchers have strived to optimize the energy storage systems operation for their different application and in different capacities. Each type of energy storage system used in an application would affect the optimization problem in a singular way. In an optimization problem, it is important to know what the objective is and in this thesis, we are addressing asset planning optimization wherein we attempt to minimize cost of energy assets such as generators and BESS to meet customer demand in distribution system. Therefore, the important thing about energy storage systems, and in this case BESS, is to keep in mind that battery efficiency and dependability is affected by its operation and how it is programmed to respond to the demands of the grid.

Applications of energy storage systems in power systems are studied extensively in the literature and there is a wide selection of research articles that have targeted the optimization of the ESS's operation. Here, we will briefly discuss some of the related research works that have been done in this area and will highlight the differences of this work with them.

As an example of other types of storage systems in distribution system, authors in [11] have introduced a new superconductive magnetic energy storage (SMES). Their scheme decreases transmission line loading, losses, fuel costs and also improves the electric power transmission especially if the SMES is located near heavy-load customers. 


\section{INTRODUCTION CHAPTER 1}

In [20], authors used multipass dynamic programming algorithms with time shift to calculate the economic dispatch of BESS and find optimal BESS power and energy capacities in a power system. Results of their research show that the use of BESS can reduce the cost for the utility systems as well as the end customers.

Another study has used similar method to achieve the optimal charging curve of a battery energy storage system [21]. Maximum payoff for load redistribution and peak load shaving is determined to ensure the minimization of the electricity bill. This work also offers a method to optimize the size the ESS for a specific application.

In [22], authors have presented a multi objective optimization to study the effects of using BESS on the "Net Present Value" of these installments in a distribution system. They have succeeded in defining the relationship between energy storage installment and battery specific costs. In this paper, several applications of energy storage system and their contribution to the economic benefits have been studied at the same time.

In [23], portable energy storage units have been used in order to postpone transformer upgrades. The objective is cost minimization and a dynamic program has been used to solve the problem. Results of this study prompts a lower battery cost is required to obtain an economically viable solution.

In another study authors claim that maximum economic benefits of BESS in power system can be achieved by using proposed method of optimizing the battery capacity [24]. In that study, thermal units have been taken into consideration but battery's internal characteristics have not been taken into account. Particularly, the results show that the BESS with high power capability and low capacity is an optimal solution in a network with large difference between the peak and base loads.

Authors in [25] are using an "exterma" method to optimize the size of the BESS

while minimizing the customer electricity cost by reducing the power demand costs using peak shaving. The authors also use dynamic programming to minimize the electricity cost maintaining the battery within its physical constraints. The battery is modeled with an 


\section{INTRODUCTION CHAPTER 1}

internal resistance that is a function of the battery's state of charge as well as the direction that the power is flowing, i.e. charge or discharge, based on the model used in [26].

In another paper Simulated Annealing (SA) algorithm with a heuristic approach was used to find the optimal size of a battery storage installed in a PV/wind integrated hybrid energy system [27]. The algorithm has been implemented on a case study to minimize the hybrid energy system total cost.

In another study, authors have introduced a method to optimize the BESS installation locations and also capacity of each energy storage device used for load leveling applications [28]. The studied system is a distribution system in Korea (the energy storage application relates to the utility side). The determining factor in the proposed method is the load factor at each main transformer in the test system. The optimal result is found by comparing the load factor improvements in the distribution subsystem.

In another reference, three different applications of BESS have been considered [29]. The dynamic operating costs have been calculated in the load frequency control, load leveling and spinning reserve applications. Economic benefits of BESS applications under different unit commitment scenarios for an island system have been studied using the costing program "DYNASTORE".

Another research work compares three applications of the BESS, load leveling, control power (also known as spinning reserve) and peak shaving, in terms of their monetary value [30]. Batteries studied in this work are lead-acid, NiCd and Vanadium Redox (VR) batteries. The purpose of the study is to determine which BESS application has more economic benefits and their results show that "control power" application has the highest monetary benefits.

In another paper, authors have used advanced multi-pass dynamic programming to determine the optimal capacity of BESS [31] for time-of-use rates customers. The 


\section{INTRODUCTION CHAPTER 1}

proposed algorithm has been tested for two of the Taiwan Power Company System customers.

In [32] a new technique called the jump and shift method has been introduced to solve the Smart Energy Management System (SEMS) multi objective optimization problem. The method is tested on a microgrid containing PV and battery banks.

Authors in [33] have developed a matrix real-coded genetic algorithm in order to solve a single-objective optimization for the Smart Energy Management System (SEMS) of a microgrid. The algorithm leads to cost optimization, economic load dispatch and optimized operation strategies.

In another study, mixed integer linear programming in General Algebraic Modeling System has been used in order to find the optimal operation of an isolated system consisting of a wind turbine, solar unit, fuel cell and a battery energy storage system [34]. A Virtual Power producer (VPP) has been used to ensure the optimal operation of generation units and the operation of ESS within its constraints.

In another study, a multi-objective algorithm has been designed via non-dominated sorting genetic algorithm (NSGA-II) to study the monetary benefits of a stand-alone micro-grid in an island in china [8]. Factors considered in this model include battery loss cost, operation and management costs, fuel and environmental costs. The battery being considered for this microgrid is a lead-acid battery. The difference between this paper and [35] is that the authors consider the effect SOC has on the cost function. A minimum and maximum has been defined for the SOC thus preventing battery's dramatic decrease in efficiency which is seen in batteries that have been charged to $100 \%$ SOC or discharged to $0 \%$ SOC. However, the effect SOC or DOD on the overall cost have been modeled by assuming a linear relationship between battery losses and SOC which is only an approximation.

Authors in [36] found that if multiple energy storage devices with complementary performance characteristics are used together, the resulting 'hybrid energy-storage 


\section{INTRODUCTION CHAPTER 1}

system' can dramatically reduce the cost of energy storage over single storage systems. Their paper has focused on the control strategy of the energy storage systems to reduce costs. The cost of storing energy with a hybrid energy-storage scheme was found to be much less than either single storage method. Two control algorithms are studied in this paper for two hybrid systems, battery plus hydrogen storage and battery plus fuel cell storage. The algorithms are:

1. SOC algorithm where battery is the number one storage device. The battery SOC is tightly controlled and the hydrogen or the fuel cell system handles the remaining energy demands. However, this algorithm might result in a larger than necessary secondary energy storage device which in turn increases the costs.

2. Neural Net $(\mathrm{NN})$ controlled algorithm that adapts to daily and seasonal changes and tries to level the loads between the two components of the storage system. This approach shows over 30\% in cost saving over the simple SOC based algorithm.

One shortcomings of [36] is that: size and cost relationship is considered linear, which is a rough estimation. In both cases battery usage is favored over the other grid connected storage units even if it is economically unadvisable. In short, the objective isn't cost optimization but instead reducing fuel usage and making the application more environmental friendly.

In another study, three stand-alone photovoltaic hybrid systems, photovoltaic/battery (PV/Battery), photovoltaic/fuel cell (PV/FC) and photovoltaic/fuel cell/battery (PV/FC/Battery) systems are analyzed [37]. The designed method is claimed to minimize system configuration and optimize the sizing of the systems. The relationship between system cost and system efficiency has been studied. It is shown that the hybrid PV/FC/Battery system provides the best trade-off in the multi-objective optimization for minimized system cost and maximized system efficiency compared to either single storage systems. 


\section{INTRODUCTION CHAPTER 1}

In [38], cost benefits of a hybrid PV-BESS in an isolated system have been studied by considering load, utility, battery and PV data and characteristics. However, there are several important factors which have not been taken into account; including: power quality, protection, reliability and security and SOC/DOD.

In [35] authors have proposed a model in order to calculate the sizing, capital costs, control strategies, and efficiencies of different types of energy storage including Reversible Fuel cell (RFC), batteries and Ultra-capacitors both individually and as a hybrid solution for a standalone PV powered consumer. The authors have highlighted the significance of the choice of control strategy for the given single or hybrid energy storage system in the overall system efficiency and cost. The authors have chosen a simplistic battery model for battery control purposes and although they have noted that SOC affects battery characteristics at any given time, no solution has been set forward to optimize the hybrid systems by taking SOC or DOD into account.

The relatively high capital cost of BESS drives the interest in extending their lifetime. Very high DOD shortens battery life-time [39]. None of the works reported in the literature consider the nonlinear relationship between life of the BESS, number of cycles per year and usage in terms of depth of discharge while optimally planning for expansion

of distribution systems to supply demand and maintaining service as required by applicable standards. This is a must for an optimal economic asset expansion plan that considers BESS. This thesis addresses optimal asset planning for distribution systems considering these aspects as outlined in the next section.

\subsection{Objectives}

In this thesis a novel optimal expansion formulation and algorithm is proposed that considers the BESS nonlinear relationship of life-cycles-usage whilst meeting energy demand in the distribution system and satisfying applicable service standards. The objective of this optimization is to minimize the total annualized asset cost for energy supply. In the end, the result would be the optimum sizes of BESS units and generators 


\section{INTRODUCTION CHAPTER 1}

to supply forecasted demand in the distribution system whilst meeting all codes and standards with respect to electricity supply.

The objective also includes study of the proposed method on two systems and exploring the effect of nonlinear BESS relationship of life in years and usage in terms of number of cycles and depth of discharge on annualized asset costs.

\subsection{Chapter-wise Summary}

In Chapter 2, the problem of optimal energy asset expansion planning for distribution systems is outlined and the theory is explained. Theoretical and mathematical models are provided and solution method is proposed based on the formulation.

In Chapter 3, the developed program has been tested on two test systems. The test systems are 6-bus synthetic system and an IEEE 33-bus distribution network with 1 and 2 generators installed respectively. The obtained results have been presented in this chapter accompanied by relevant tables, graphs and explanations.

Chapter 4 offers the conclusion of this work. The main achievements and novelties of this work are highlighted in this chapter. The "Future works" section offers suggestions and a guide to anyone wishing to further research this topic.

\subsection{Chapter summary}

In this chapter, the necessity and benefits of energy storage have been explored. Different types of energy storage have been presented and the reasons for choosing Lithium-ion battery as the desired type of energy storage have been stated. Similar works done in the literature and a brief overview of each work highlighting its pros and cons have been presented.

The objective of this thesis is to find the optimum asset plan, which is size of the BESS units and generators to minimize the annualized asset costs. 


\section{CHAPTER 2}

\section{THEORY AND FORMULATION}

\subsection{Introduction}

Expected life-time of the battery is directly dependent on many internal and external factors. Manufacturing quality, type of the battery (ions being used) and chemistry are examples of some of the internal factors which are typically out of hand and we cannot interfere with. On the other hand, operating temperature, charge method, quality of maintenance, SOC levels in each cycle and cycling regime can be controlled by the operator and finding the optimum operating point of each of these parameters would have an impact on the battery performance [40].

\subsection{BESS characteristics}

The BESS usually comprises of battery cassettes with cells in series. These cassettes are connected in series to form a string of a desired voltage. Several strings of same build are connected in parallel to adjust the module power capabilities. A review of literature shows that depth of discharge and number of cycles per year, impact the lifetime of the BESS [41]. In general, they have a nonlinear effect as shown in Figure 2-1. Accordingly, when the BESS is restricted within a range of operation in terms of depth of discharge and number of cycles per year, the resulting relationship appears as below [41]:

$D O D_{k} \cdot N C_{k} \cdot N Y_{k}=$ EConst $_{k} \quad \forall k$

To get Number of Cycles per day, one only needs to divide Number of Cycle per year by 365 . NC in the rest of this thesis refers to the latter. The problem formulation presented in this paper uses this equation to constrain its use to achieve a realistic optimal asset expansion plan considering BESS and new sources of energy. 


\section{THEORY and FORMULATION CHAPTER 2}

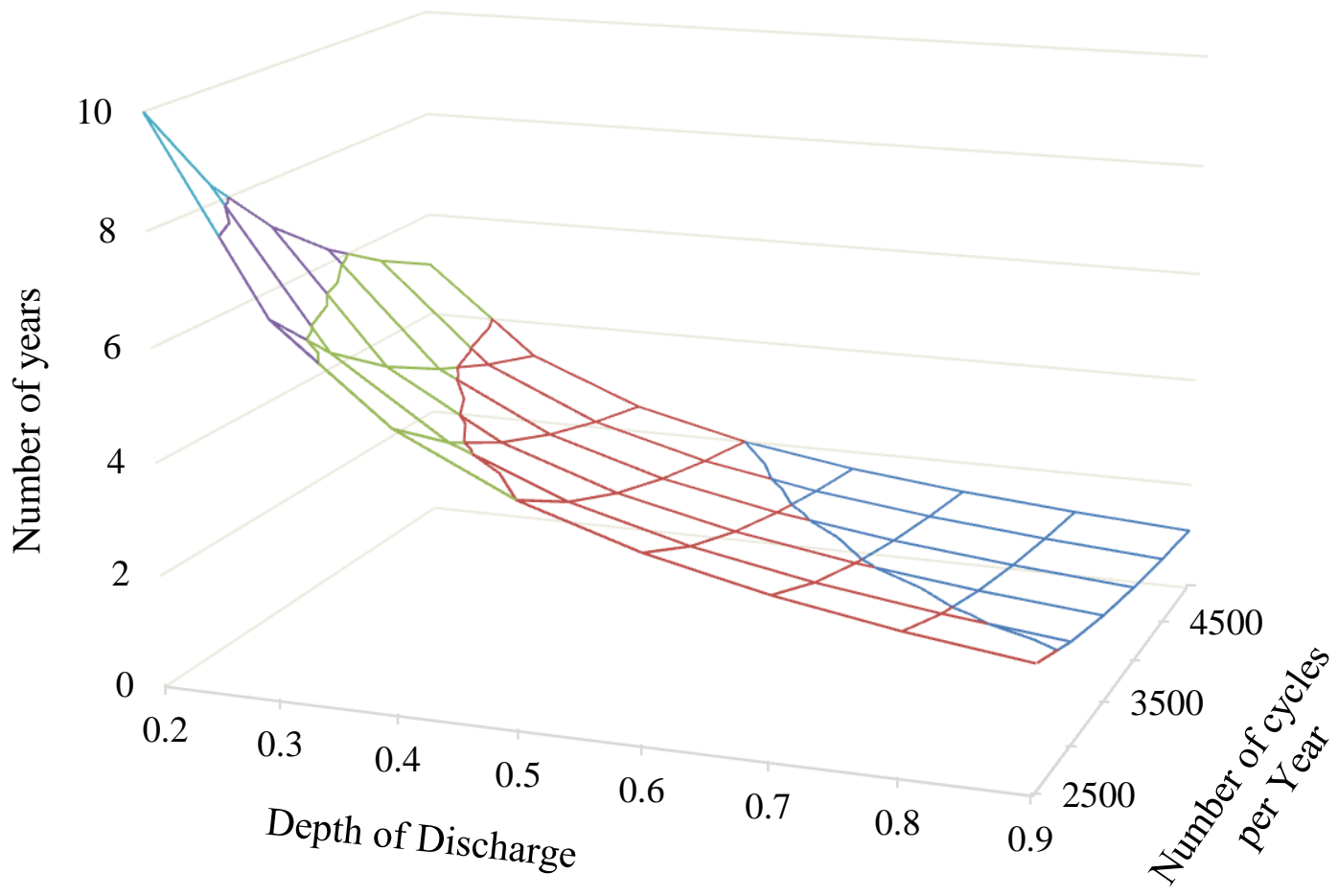

Figure 2-1 BESS relationship between life in number of years with usage in terms of number of cycles per year and depth of discharge

\subsection{Problem Formulation}

This study considers the problem of sizing new generators and BESS for supplying energy to forecasted demand such that distribution system lines and cables are adequate while satisfying applicable operational requirement as per standard codes. The BESS performance is modeled by considering the effect of usage in terms of depth of discharge and number of cycles per year on the life using (2.1).

\subsubsection{Objective Function}

In this optimal asset expansion plan, the objective is to minimize annualized costs of generation assets and BESS assets: 
$\min \left[\sum_{i=1}^{N G} C G \cdot \overline{P G_{i}}+\sum_{k=1}^{N E} \frac{C E P \cdot \overline{P E_{k}}+C E E \cdot \overline{E E_{k}}}{N Y_{k}}\right]$

where $\overline{P G_{i}}$ represents the maximum power capacity of the generator i. The terms $\overline{P E_{k}}$ and $\overline{E E_{k}}$ serve as power and energy capacities of the BESS respectively and represent the maximum value for energy and power of the BESS.

The cost coefficient CG represents annualized cost coefficient for generators. The BESS capital cost coefficients CEP and CEE have units of \$/MW and $\$ / M W h$ respectively. The optimization challenge is to account for annualized cost for capital required to provide the grid with the demand. To compute annualized capital cost of the BESS, its related expressions in the (2.2) have been divided by the life-time of the BESS in years, $N Y_{k}$. The cost coefficients have been shown in Table 2-1.

Table 2-1 Generator and BESS cost coefficients [42]

\begin{tabular}{ccc}
\hline $\mathrm{CG}(\$ / \mathrm{KW})$ & $\mathrm{CEE}(\$ / \mathrm{KWh})$ & $\mathrm{CEP}(\$ / \mathrm{KW})$ \\
\hline 2,000 & 2,100 & 150 \\
& & \\
\hline
\end{tabular}

\subsubsection{Constraints}

In (2.2), the term $\overline{P G_{i}}$ represents the maximum power capacity of the generator $\mathrm{i}$ during any time of its operation with a power $P G_{i h}$. Accordingly, it is determined via the following constraint:

$0 \leq P G_{i h} \leq \overline{P G_{i}}, \quad \forall i, \forall h$

In (2.2), $\overline{P E_{k}}$ and $\overline{E E_{k}}$ serve as power and energy capacity of BESS and represent the maximum value for energy and power from BESS. Therefore, (2.4) and (2.5) can be used as constraints in this problem to limit the two variables PE (BESS power) and EE (BESS energy). 
$-\overline{P E_{k}} \leq P E_{k h} \leq \overline{P E_{k}}, \quad \forall k, \forall h$

$0.01 \cdot \overline{E E_{k}} \leq E E_{k h} \leq 0.99 \cdot \overline{E E_{k}}, \quad \forall k, \forall h$

where $P E_{k h}$ and $E E_{k h}$ represent power and energy of BESS at bus $\mathrm{k}$ in time zone $\mathrm{h}$. Further, the energy in the BESS is restricted between 1\% and 99\% of its energy capacity [8]. In order to ensure that BESS stores and returns energy without consuming or supplying energy, the total energy in the end must equal that of the start, without specifying a value, where this value is optimized to be the most effective value via the optimization:

$E E_{k, h=0}=E E_{k, h=N H}, \quad \forall k$

Further, considering a storage efficiency parameter of $\alpha$ that accounts for selfdischarge time, the amount of energy in a BESS as a function of past stored energy and energy input for the hour can be expressed as below:

$\alpha \cdot E E_{k, h-1}+P E_{k h}=E E_{k h}, \forall k, \forall h$

In addition, in order to model the distribution system's network, bus-wise complex power balance equations should be satisfied:

$S G_{i h}-S D_{i h}-P E_{k \epsilon i, h}=S T_{i h}, \forall i, \forall h$

where $S G_{i h}$ and $S D_{i h}$ are the apparent generation and demand at bus $\mathrm{i}$ in time zone $\mathrm{h}$. The term $S T_{i h}$ represents the net apparent power flowing from bus $\mathrm{i}$ in time zone $\mathrm{h}$ into the connected transmission system. The BESS is assumed to provide only real power at unity power factor.

The complex vector $S T_{h}$ for hour h can be computed by using the vector of voltage phasors and bus admittance matrix:

$S T_{h}=V_{h} \cdot\left(Y B \cdot V_{h}\right)^{*}$ 


\section{THEORY and FORMULATION CHAPTER 2}

Further, magnitude of bus voltage phasors should be within applicable standards as described below:

$\underline{V} \leq\left|V_{i h}\right| \leq \bar{V}$

In addition, apparent power flow through lines should be restricted within their respective maximum capacities as below:

$\left|V_{i h} \angle \delta_{i h} \cdot\left[\left(V_{i h} \angle \delta_{i h}-V_{j h} \angle \delta_{j h}\right) \cdot y_{l}\right]^{*}\right| \leq \overline{S L_{l}} \quad \forall l, \forall h, \quad(i, j) \in l$

where $\overline{S L_{l}}$ represents the maximum MVA line flow through line $l$ which is connected between busses $\mathrm{i}$ and $\mathrm{j}$. The line $l$ admittance is described by $y_{l}$.

Further, the main novelty of this work is taking BESS relationship between life in number of years and usage quantified via depth of discharge (DOD) and number of cycles per year into consideration. DOD represents the depth of discharge and can be calculated from the equation below:

$D O D_{k}=\frac{\max \left(E E_{k h}\right)-\min \left(E E_{k h}\right)}{\overline{E E_{k}}} \quad \forall k, \quad \forall h$

where $\max \left(E E_{k h}\right)$ represents the maximum energy stored in the BESS of bus $\mathrm{k}$ considering all hours of operation. The exact relationship between DOD and BESS life is needed to determine the optimum cycling regime. The relationship can be seen in (2.1), where $\mathrm{NC}$ is the number of cycles per day and NY is the number of years the BESS is expected to be in a healthy condition. This equation has been derived from the work done by the authors in [41].

Also, battery's number of cycles per day can be found from (2.13) where charging is compared with energy capacity of BESS. As can be seen, the number of cycles per day depends on the size and energy capacity of the BESS. 
$N C_{k}=\frac{\left[\sum_{h=1}^{N H}\left|P E_{k h}\right|\right]}{2 \overline{E E}_{k}} \quad \forall k, \quad \forall h$

The formulation with the objective described in (2.2) and constraints (2.1), (2.3)(2.13) can be solved using any optimization software.

\subsection{Solution method}

The OPF problem is now formulated as an objective function (2.2) and a set of constraints (2.1) and (2.3) - (2.13). Objective of this problem is to find the optimal BESS and generator sizes. Since the program contains non-linear constraints, it was found best to use MATLAB's fmincon solver. Fmincon is an iterative solver and for the purpose of this problem, the "interior point" algorithm (former Barrier Method) was used. This algorithm is used to solve linear and non-linear convex optimization problems. The steps in this algorithm are as below [43]:

- Step 1: Initialization

Start with a feasible point and set the iteration counter $\mathrm{s}=1$.

- Step 2: Optimality Test

The gap between the dual and primal objectives defined by the algorithm is calculated and then compared to the tolerance value $\varepsilon$. If gap is smaller than $\varepsilon$, stop; else proceed to step 3 .

- Step 3: Compute the Direction

- Step 4: Find Step Length

Step length or $\Delta \mathrm{X}$ is found. $\mathrm{X}$ consists of all the variables $\mathrm{PG}, \mathrm{QG}, \mathrm{PE}$, EE, EEMax, PEMax, NY, V (voltage magnitude) and DEL (voltage angle); therefore all the variations of these parameters are found.

- Step 5: Update Solution

Using the $\Delta \mathrm{X}$ found in the previous step, the new value of $\mathrm{X}$ is calculated. $\mathrm{X}^{\mathrm{s}+1}=\mathrm{X}^{\mathrm{s}}+\Delta \mathrm{X}$ 


\section{THEORY and FORMULATION CHAPTER 2}

- Step 6: Update iteration step from $\mathrm{s}$ to $\mathrm{s}+1$ and repeat step 2.

The vector $\mathrm{X}$ is the vector of variables in this program and consists of the following variables: PG, QG, PE, EE, $\overline{E E}, \overline{P E}, \mathrm{NY}, \mathrm{NC}, \mathrm{DOD}, \mathrm{V}$ and DEL (Voltage angle). After the final iteration, the final results for each of the elements in the $\mathrm{X}$ vector are found.

The problem with this algorithm is that it can sometimes give a local minimum answer as the final result. In order to overcome this problem, GlobalSearch has been used in MATLAB. By utilizing this function, several initial values are chosen and the solutions are compared and the answer resulting in the lowest fval is declared as the best answer.

\subsection{Chapter summary}

In this chapter the theory behind this work has been explained. Problem outline has been explained and mathematical formulations have been offered in terms of the objective function, linear and nonlinear constraints.

In the next chapter, the problem has been studied on two different test systems. These test systems and their differences have been explained and the MATLAB simulation results are provided. 


\section{CHAPTER 3}

\section{RESULTS}

\subsection{Introduction}

In this chapter, the asset expansion problem with the objective function (2.2) is evaluated on two test systems. The first system has been especially designed by the author for the purpose of testing the formulation and program. The second system is an IEEE 33-bus radial distribution system. The battery in both cases is assumed to have $100 \%$ efficiency and other than self-discharging, the only factors affecting its degrading, are considered to be depth of discharge and the number of cycles. The main concern in both cases is the sudden load peak in the second time zone and it is of interest to us to study the battery's behavior when the load profile contains a sudden peak. It can be seen that the introduction of a BESS into the system means that the battery costs are included in the overall costs and still the total cost decreases.

\subsection{Test System 1: 6 Bus Synthetic System}

This test system consists of 6 buses and 1 generator. A battery has also been placed at bus 3 (Figure 3-1).

The bus-wise load profiles have been scaled up and down during the day as shown in Figure 3-2 and Figure 3-3 for real and reactive power. The purpose of this is to synthesize a daily load profile.

In order to solve the asset expansion problem in this system, the 24 hours in a day have been divided into three time zones with off-peak from hours 1 to 12, mid-peak from hours 13 to 20 and on-peak from hours 21 to 24 . 


\section{RESULTS}

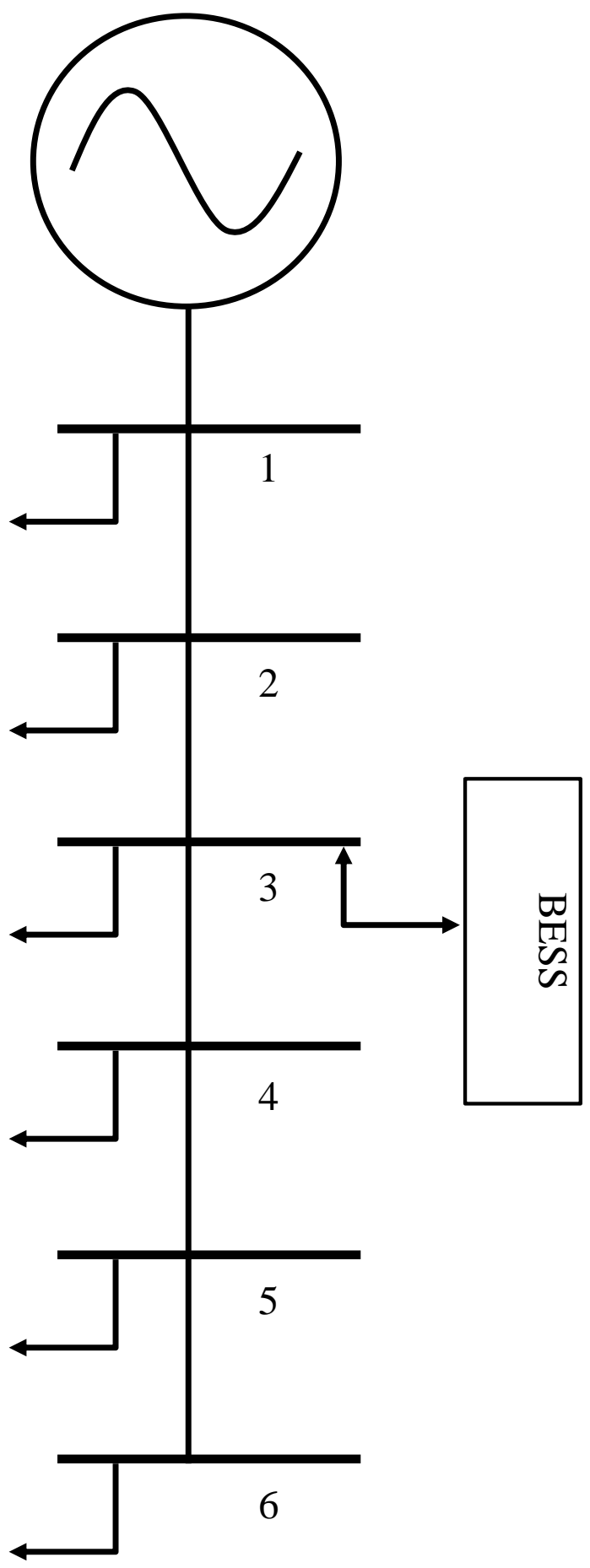

Figure 3-1 Test System 1: 6 Bus synthetic system 
RESULTS

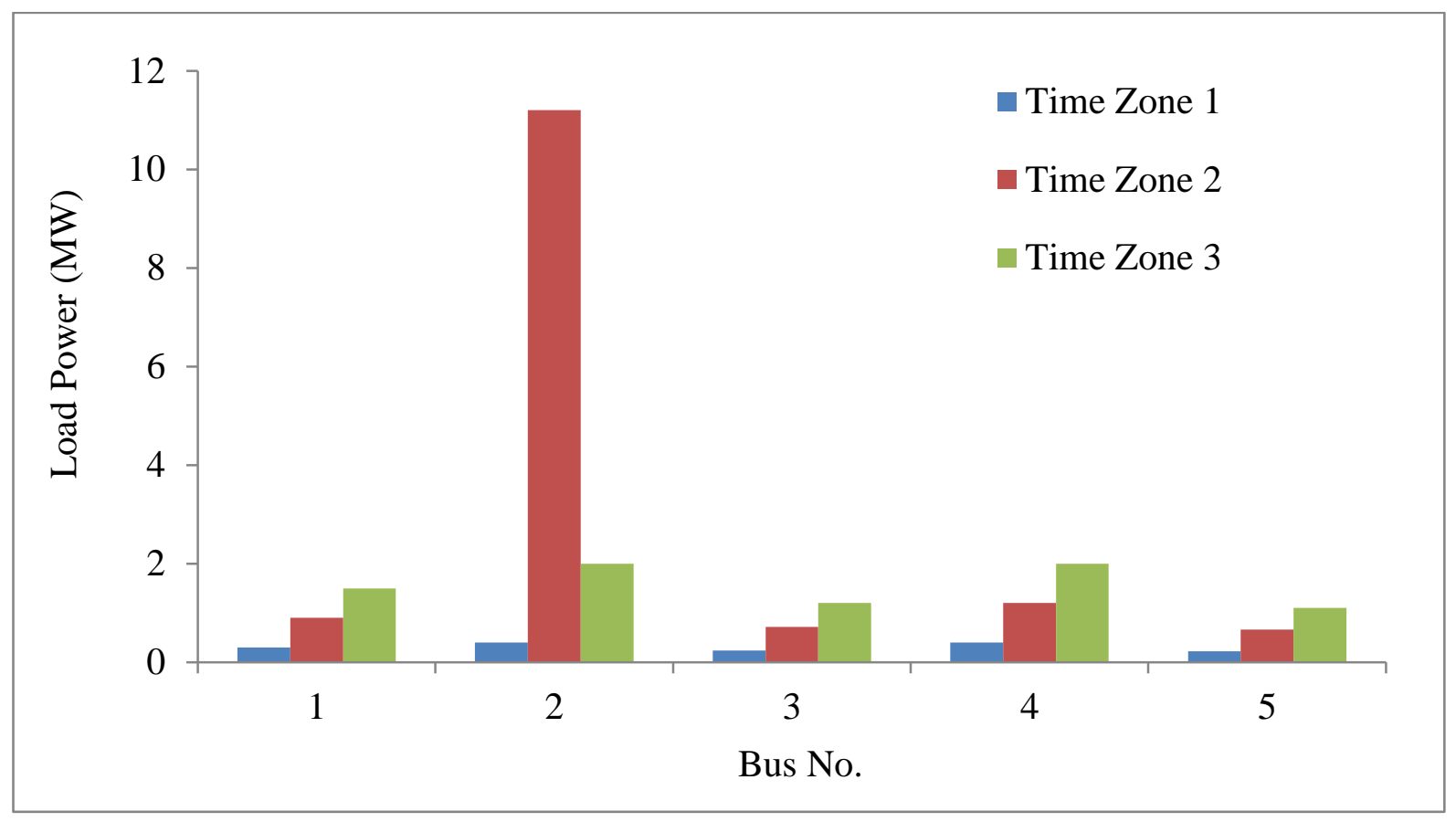

Figure 3-2 Real power loads at each bus in every time zone

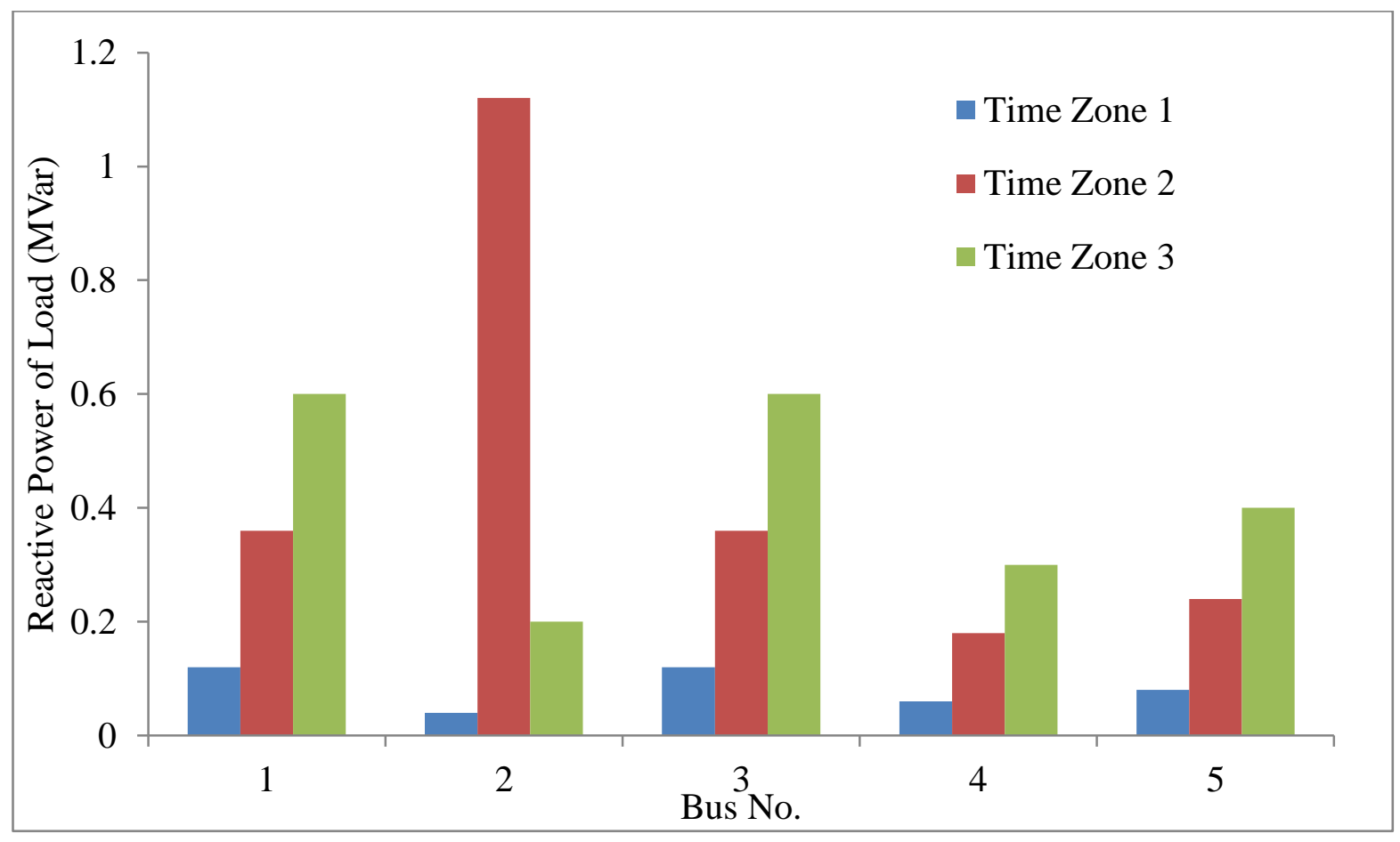

Figure 3-3 Reactive power loads at each bus in every time zone 


\section{RESULTS}

It can be seen that load on the bus 2 has a very large peak. For this reason, the BESS has strategically been placed at this bus. As can be seen, zone one represents offpeak. In Ontario (Canada), off-peak usually starts late evenings from $10 \mathrm{pm}$ and lasts until 8 am in following morning. Mid-peak starts from 9 am and lasts until 5 pm; on-peak is during the evening hours of $6 \mathrm{pm}$ to $9 \mathrm{pm}$.

The first bus in the system has the generator and is thus load-free. The buses numbered 1-5 are the load buses which correspond with buses 2-6 in Figure 3-1.

The results of running program on this test system have been offered in Table 3-1 and Table 3-2 below. Table 3-3 shows the voltage phasors for each of the buses in each of the 3 time zones. The slack bus voltage is assumed to be $1 \angle 0$ per unit in order to solve this problem. The generator and BESS results have been presented in Figure 3-4 and Figure 3-5.

Table 3-1 Generator and BESS energy in each of the three time zones

\begin{tabular}{|c|c|c|c|}
\cline { 2 - 4 } \multicolumn{1}{l|}{} & Time Zone 1 & Time Zone 2 & Time Zone 3 \\
\hline Real Power Output of Generators (MW) & 8.0524 & 8.0524 & 8.0505 \\
\hline Reactive Power Output of Generators (MVAr) & 0.4384 & 2.2795 & 2.1214 \\
\hline Real Power Output of BESS (MW) & -6.4563 & 6.6656 & -0.2093 \\
\hline Energy stored in the BESS (MWh) & 7.1511 & 0.6948 & 7.3604 \\
\hline
\end{tabular}




\section{RESULTS}

Table 3-2 BESS Characteristics for the 6 bus system

\begin{tabular}{|c|c|}
\hline Cycles per Day (NC) & 0.8164 \\
\hline Depth of Discharge, DOD (\%) & 0.8164 \\
\hline Energy Capacity of BESS (MWh) & 8.1642 \\
\hline Power Capacity of BESS (MW) & 6.66 \\
\hline Number of Years (NY) & 15 \\
\hline
\end{tabular}

Table 3-3 voltage magnitude and phase angle in each of the three time zone for the 6 bus system

\begin{tabular}{|c|c|c|c|}
\cline { 2 - 4 } \multicolumn{1}{c|}{} & Time Zone 1 & Time Zone 2 & Time Zone 3 \\
& Voltage in p.u. & Voltage in p.u. & Voltage in p.u. \\
\hline BUS 1 & $1 \angle 0^{\circ}$ & $1 \angle 0^{\circ}$ & $1 \angle 0^{\circ}$ \\
\hline BUS 2 & $0.9992 \angle-0.0003^{\circ}$ & $0.9991 \angle-0.0002^{\circ}$ & $0.9991 \angle-0.0002^{\circ}$ \\
\hline BUS 3 & $0.9953 \angle-0.0021^{\circ}$ & $0.9951 \angle-0.001^{\circ}$ & $0.9955 \angle-0.0011^{\circ}$ \\
\hline BUS 4 & $0.995 \angle-0.0022^{\circ}$ & $0.994 \angle-0.0012^{\circ}$ & $0.9937 \angle-0.0014^{\circ}$ \\
\hline BUS 5 & $0.9947 \angle-0.0023^{\circ}$ & $0.9932 \angle-0.0014^{\circ}$ & $0.9924 \angle-0.0017^{\circ}$ \\
\hline BUS 6 & $0.9944 \angle-0.0024^{\circ}$ & $0.9925 \angle-0.0017^{\circ}$ & $0.9912 \angle-0.0022^{\circ}$ \\
\hline
\end{tabular}




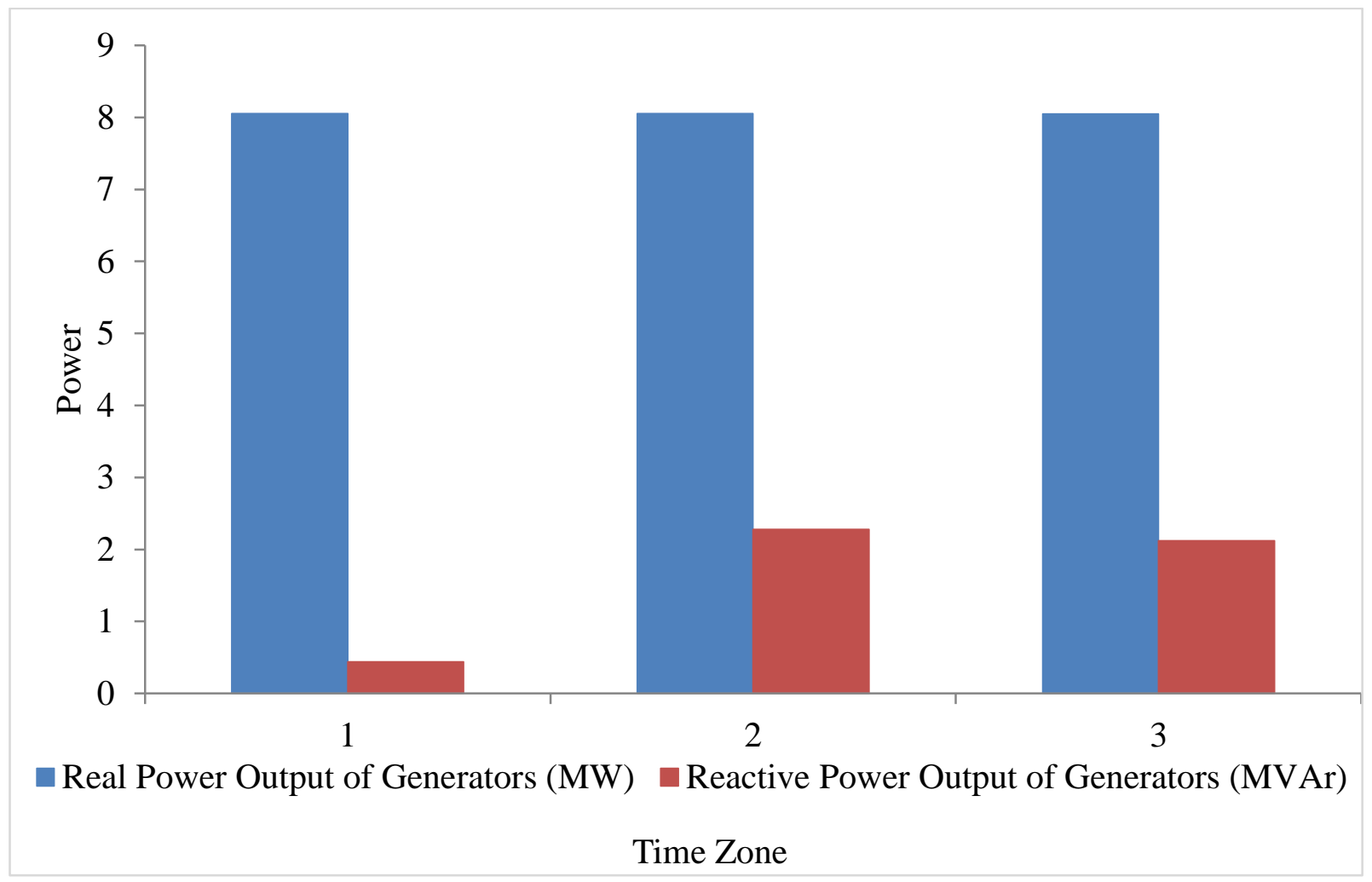

Figure 3-4 Generated real and reactive power in each of the three time zones

This analysis is performed to compare the cost of the system with and without the addition of BESS. Table 3-4 shows the total cost of the system under this test system's conditions and in the case where only a generator could be used without a BESS. In Figure 3-6, the comparison between the generated power with and without BESS in the test system 1 can be seen. 
RESULTS

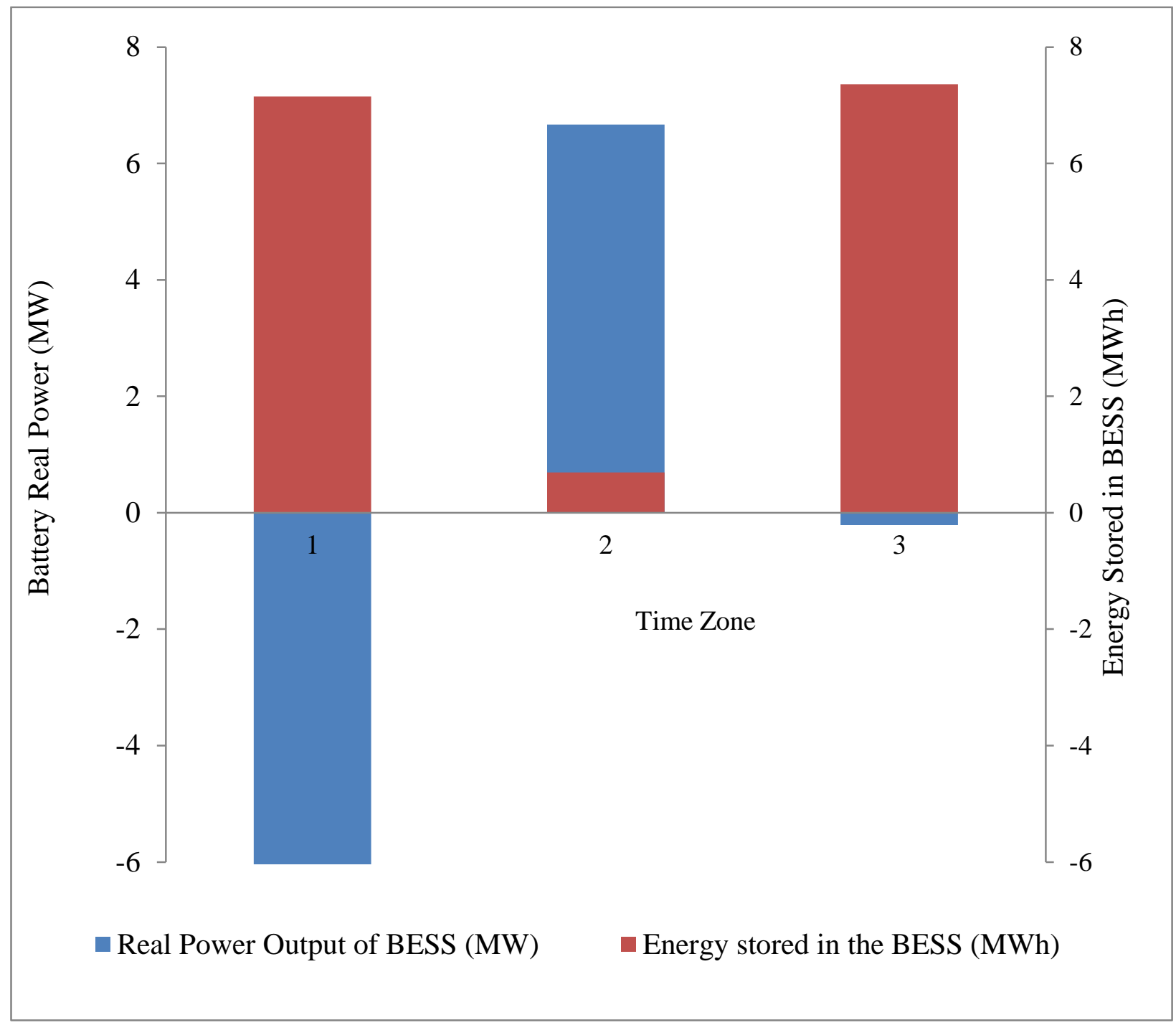

Figure 3-5 BESS real power and energy at the beginning of the time zones for the 6 bus synthetic system

Table 3-4 System cost with and without the use of a BESS for the test system 1

\begin{tabular}{|c|c|c|}
\hline & Cost of energy assets with BESS in (\$) & Cost energy assets without BESS (\$) \\
\hline Cost & 17,100 & 35,470 \\
\hline
\end{tabular}




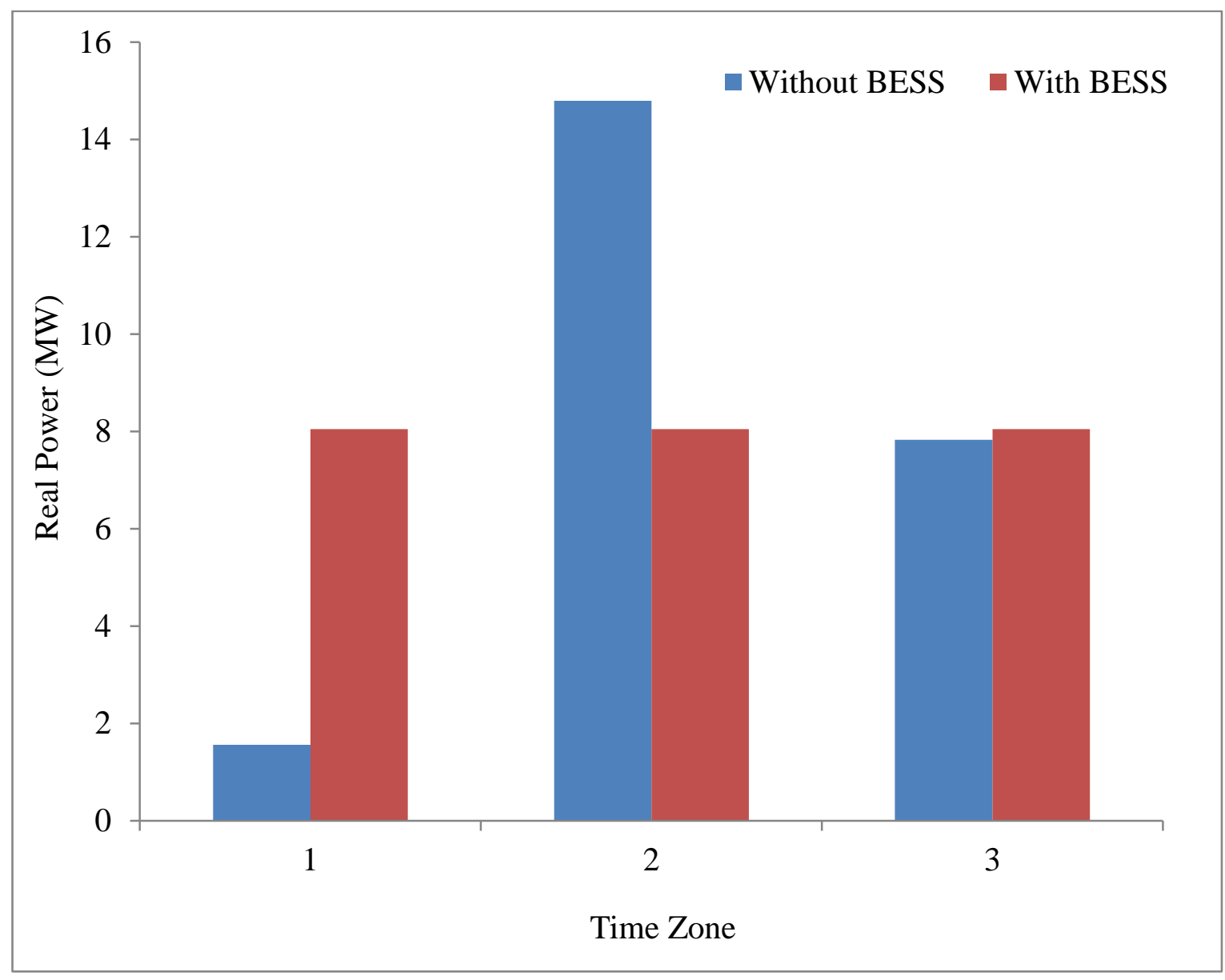

Figure 3-6 Generated power with and without BESS in the 6-bus distribution system

By rounding results in Table 3-1 for maximum energy capacity of BESS and maximum power capacity of BESS found in this test system, it is obvious that the optimal BESS size should be chosen with the characteristics shown in Table 3-5.

Table 3-5 BESS size found for 6-bus synthetic system

\begin{tabular}{|c|c|c|}
\cline { 2 - 3 } \multicolumn{1}{c|}{} & Energy Capacity (MWh) & Power Capacity (MW) \\
\hline BESS size & 8.5 & 7 \\
\hline
\end{tabular}




\section{RESULTS}

\subsection{Test System 1 (6-Bus) Sensitivity Analysis}

A sensitivity analysis has been performed for the 6 bus system. Considering all the same parameters and the same maximum system load, the minimum system load is increased in steps. The BESS and generator size have been found for different load ratios (Figure 3-7). When the off-peak to peak load ratio is low, BESS stores energy from a generator. This stored energy in BESS is used to supply energy to the load along with the generator during peak hours. It helps to reduce generator size by using BESS. It must be observed that energy arbitrage provides value for BESS when compared to generator capital costs.

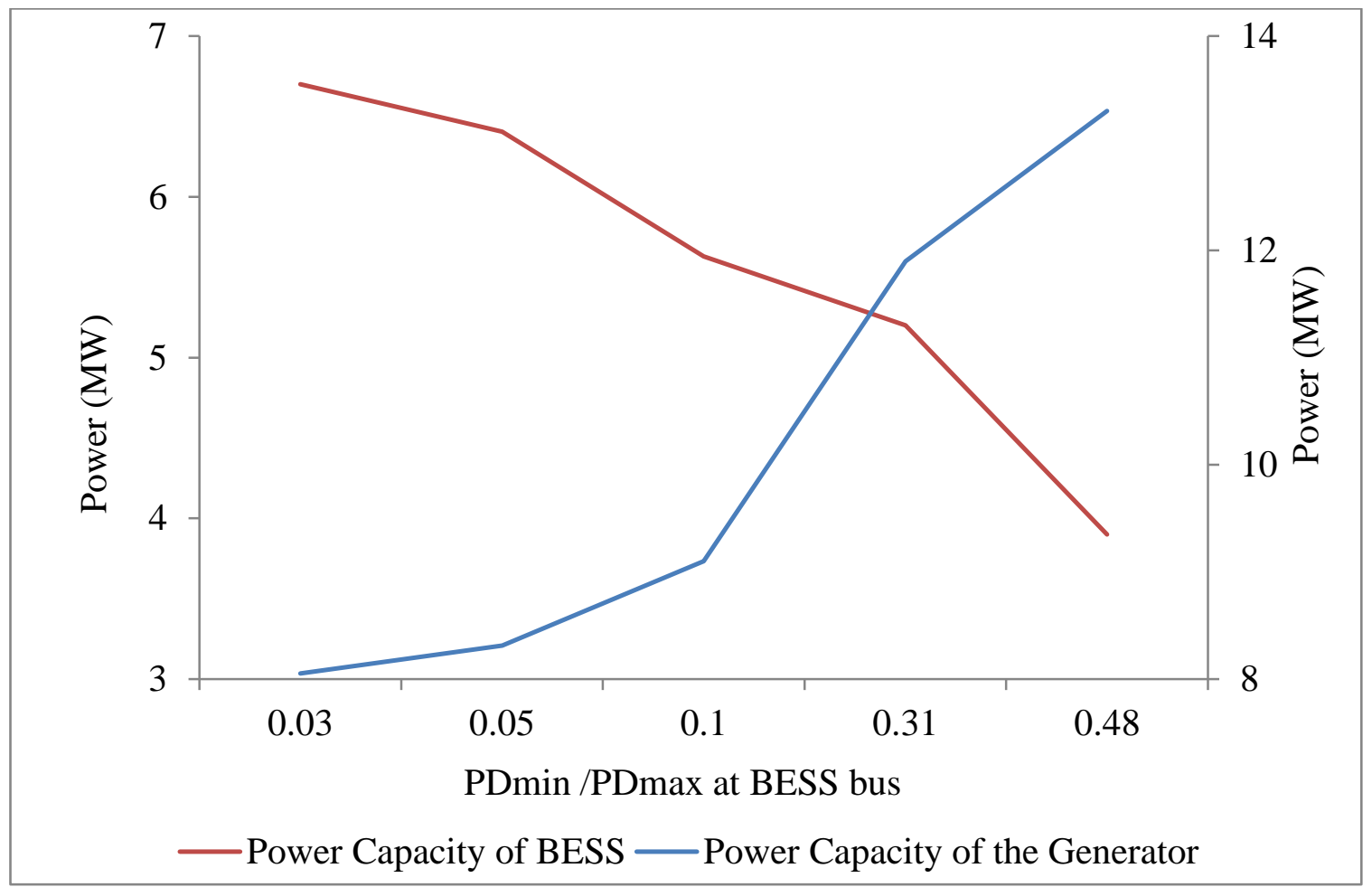

Figure 3-7 BESS and Generator size for different ratio of off-peak to peak load 


\section{RESULTS}

\subsection{Test System 2: 33-Bus System}

The second test system used is an IEEE standard 33 bus system with one generator. Load profile of this test system can be seen in Figure 3-8 and Figure 3-9. Two BESS units have been put on two different buses 3 and 15 ( 2 and 14 in the graphs). These two locations were chosen as suitable BESS locations mostly because it had been predicted that they would be experiencing sudden load peaks in the second time zone. Optimal power exchanges for the BESS and optimal power generated from the generator have been listed in Table 3-6 and Table 3-7. BESS characteristics such as number of years and cycles resulting from BESS operation have been listed as well. The changes in power and energy from BESS units, real and reactive power from generator have been shown Figure 3-10, Figure 3-11 and Figure 3-12.

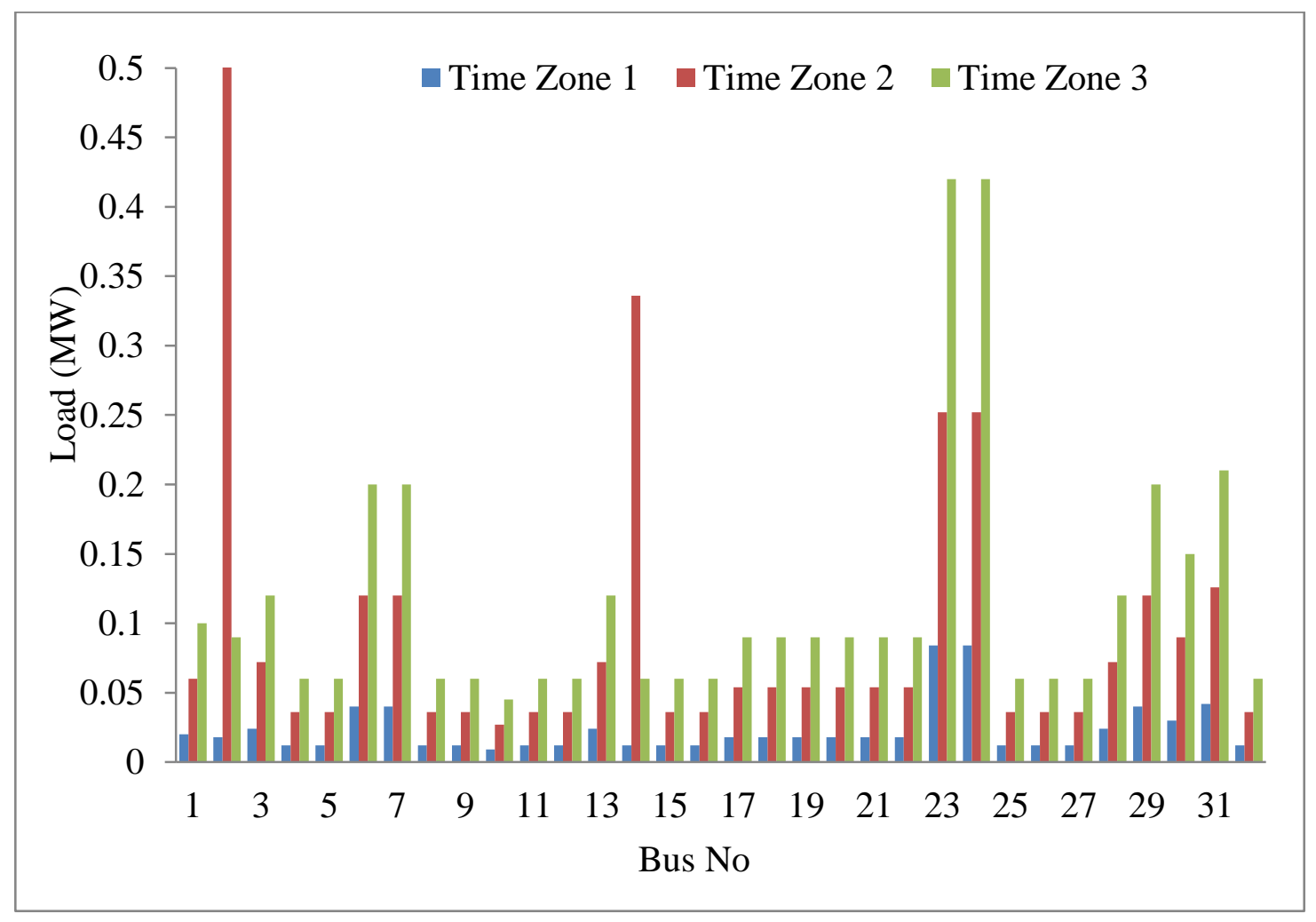

Figure 3-8 Real power load profile for the 33 bus system in each time zone 


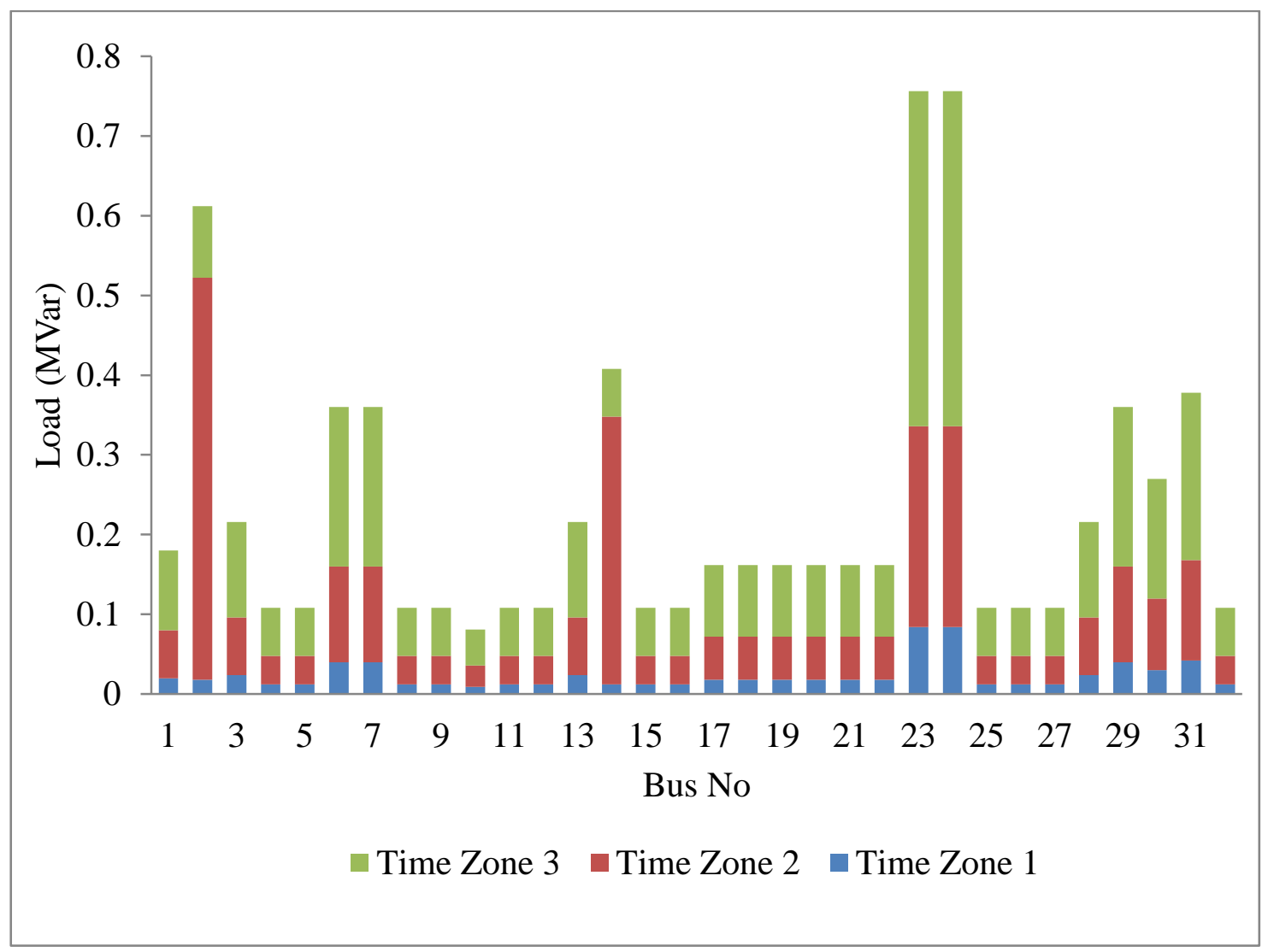

Figure 3-9 Reactive power load profile for the 33-bus system in each time zone

Table 3-6 BESS characteristics found for test system 2

\begin{tabular}{|c|c|c|}
\cline { 2 - 3 } \multicolumn{1}{c|}{} & BESS 1 & BESS 2 \\
\hline Cycles per Day, NC & 0.5335 & 0.73 \\
\hline Depth of Discharge, DOD (\%) & 0.5335 & 0.73 \\
\hline Energy Capacity of BESS (MWh) & 0.6684 & 1.817 \\
\hline Power Capacity of BESS(MW) & 0.3638 & 1.3265 \\
\hline Number of Years (NY) & 28.1 & 15.01 \\
\hline
\end{tabular}


Table 3-7 Generator power and BESS power and energy found for the 33 bus test system

\begin{tabular}{|c|c|c|c|c|}
\hline & & \multirow{2}{*}{$\begin{array}{c}\text { Time Zone } \\
1\end{array}$} & \multicolumn{2}{|c|}{ Time Zone Time Zone } \\
\hline & & & 2 & 3 \\
\hline & Real Power Output of Generators (MW) & 2.6079 & 2.6079 & 2.6079 \\
\hline & $\begin{array}{l}\text { Real Power Output of Generators } \\
\text { (MVAr) }\end{array}$ & 0.5981 & 1.6798 & 2.3877 \\
\hline \multirow[t]{2}{*}{ BESS 1} & Real Power Output (MW) & -0.3566 & 0.0617 & 0.2949 \\
\hline & Energy stored (MWh) & 0.6674 & 0.3108 & 0.3725 \\
\hline \multirow[t]{2}{*}{ BESS 2} & Real Power Output (MW) & -1.3264 & 0.3853 & 0.9411 \\
\hline & Energy stored (MWh) & 1.8154 & 0.489 & 0.8743 \\
\hline
\end{tabular}

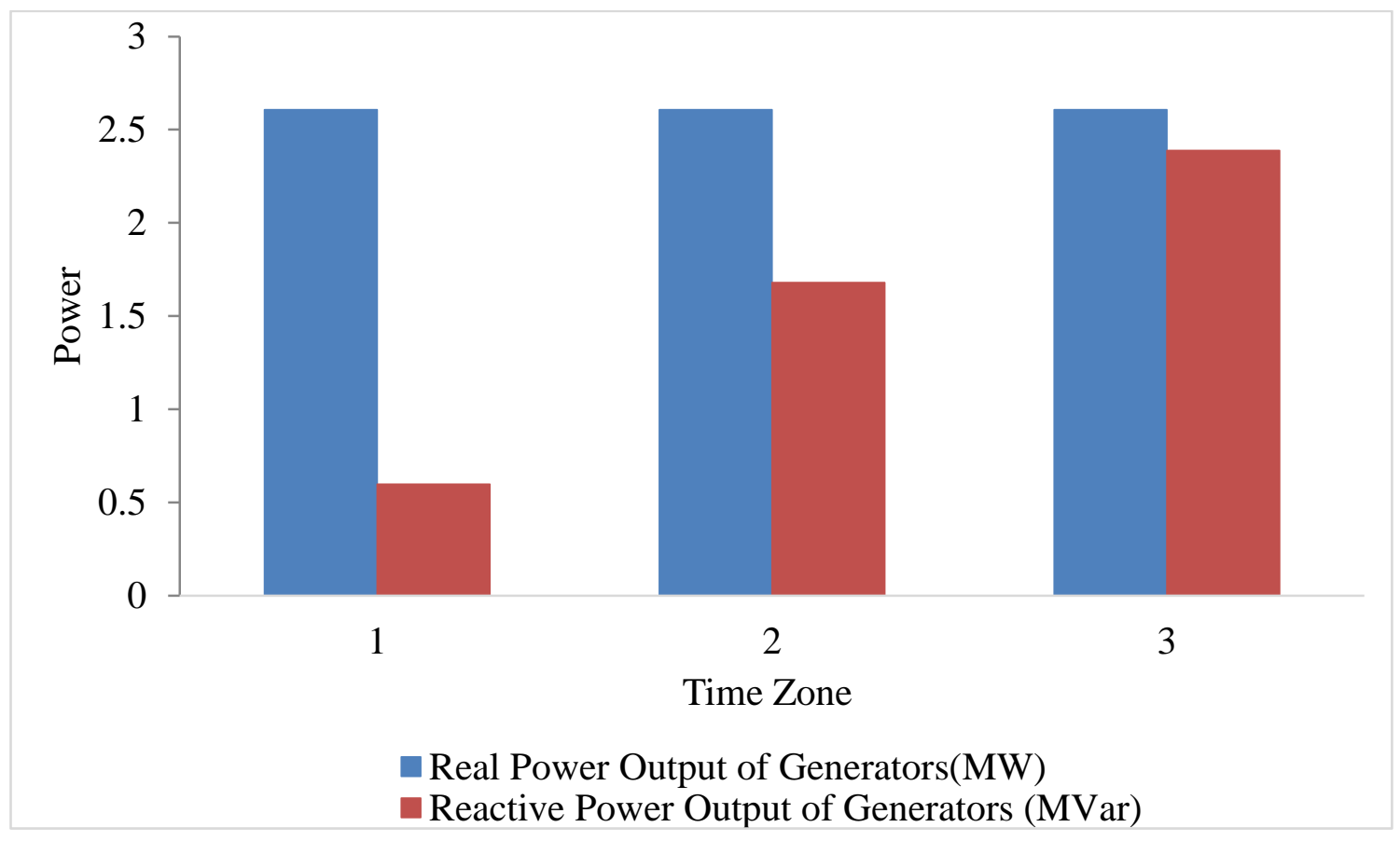

Figure 3-10 Generated power for tests system 2 
RESULTS

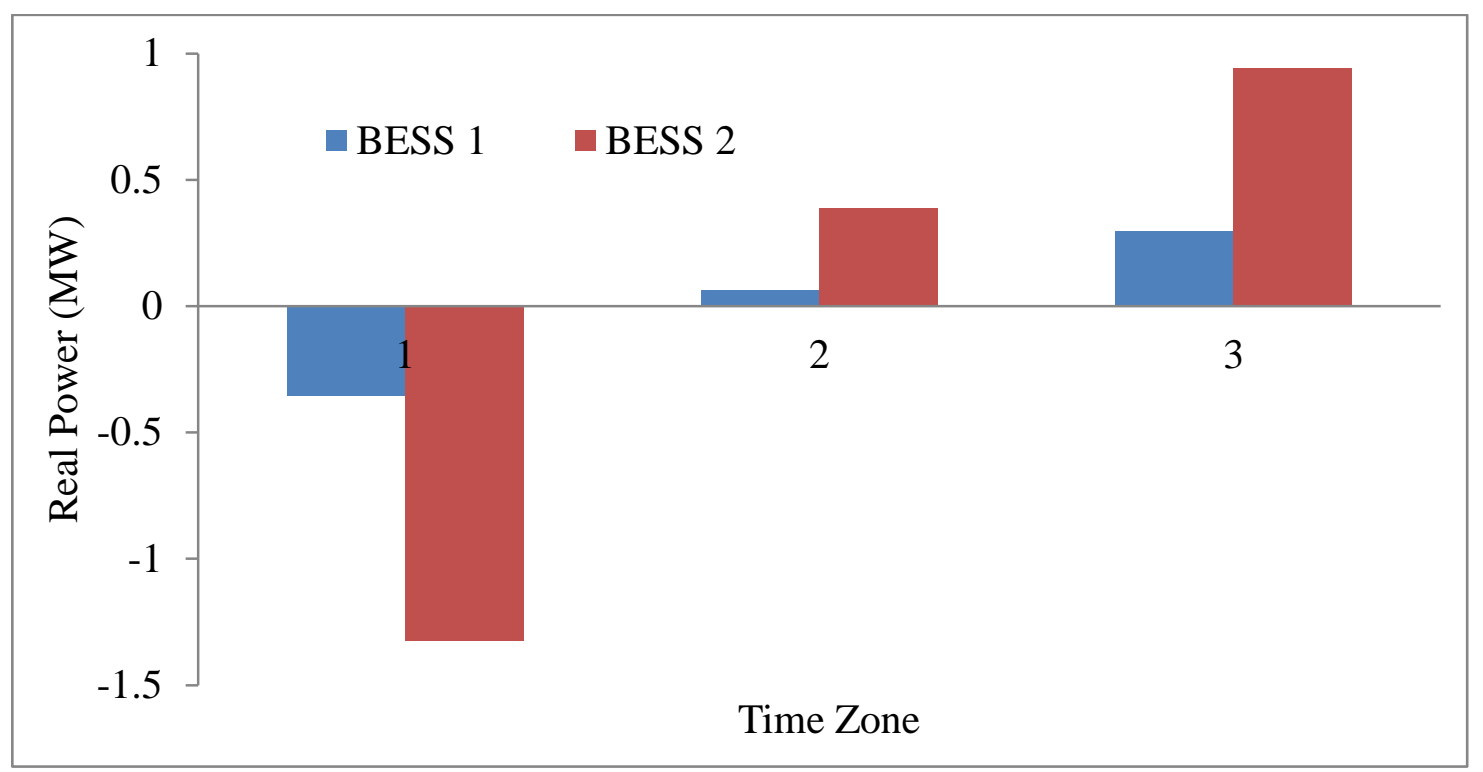

Figure 3-11 BESS power for test system 2 (33-bus) in each of the three time zones

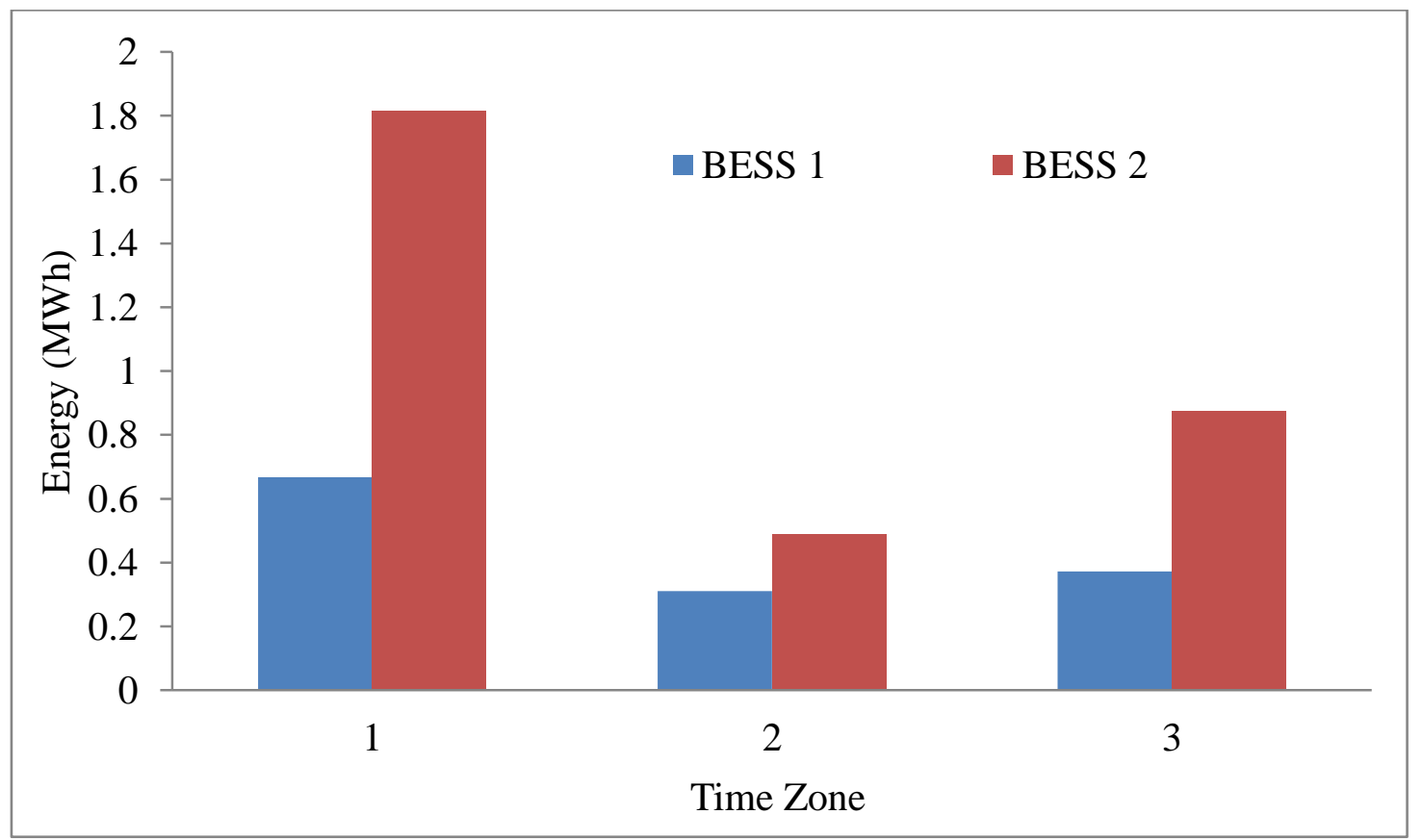

Figure 3-12 BESS energy at the beginning of each time zone for test system 2

Cost of the energy with and without the addition of BESS for the 33-bus system can be seen in Table 3-8. Figure 3-13 below shows the generated power in the 33 bus system in both cases of with and without the contribution of BESS in the distribution 
system. Taking results from Table 3-7 and rounding it up, the maximum energy capacity of BESS and maximum power capacity of BESS found in this test system, the optimal BESS size would have the parameters as shown in Table 3-9.

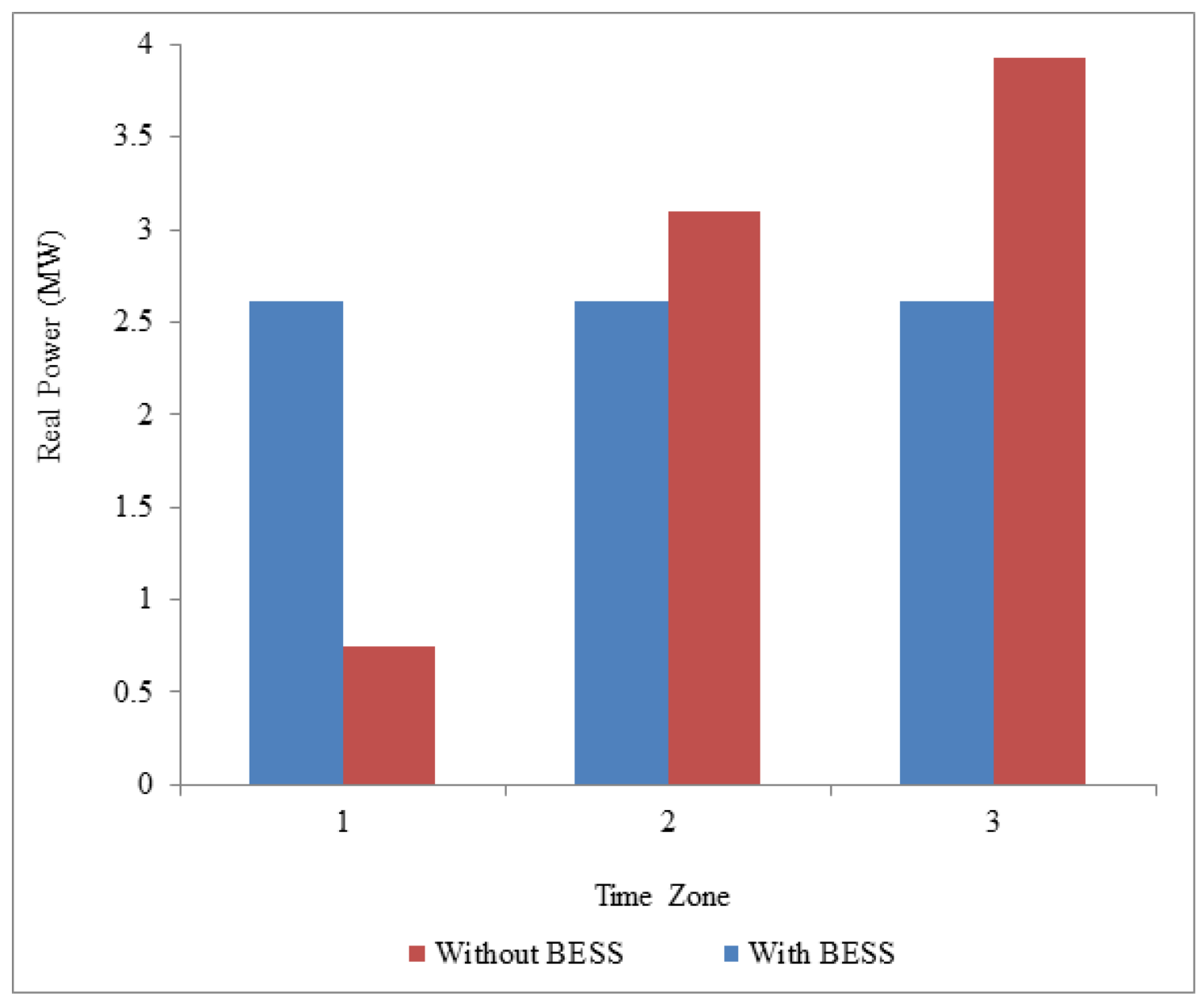

Figure 3-13 Generated power with and without BESS in the 33 bus distribution system 


\section{RESULTS}

Table 3-8 System cost with and without the use of a BESS for the 33 bus system

\begin{tabular}{|c|c|c|}
\hline $\begin{array}{c}\text { System } \\
\text { type }\end{array}$ & $\begin{array}{c}\text { Cost of energy assets with BESS in } \\
(\$)\end{array}$ & $\begin{array}{c}\text { Cost energy assets without BESS } \\
(\$)\end{array}$ \\
\hline Cost & 5,450 & 10,103 \\
\hline
\end{tabular}

Table 3-9 BESS size found for the 33-bus System

\begin{tabular}{|c|c|c|}
\cline { 2 - 3 } \multicolumn{1}{c|}{} & Energy Capacity (MWh) & Power Capacity (MW) \\
\hline BESS 1 & 0.7 & 0.4 \\
\hline BESS 2 & 2 & 1.4 \\
\hline
\end{tabular}

\subsection{Test System 2 (33-Bus) Sensitivity Analysis}

The ratio of off-peak to peak load is once again increased for the 33-bus system while keeping the peak load constant. Effect of this change is observed on the optimal sizes of BESS units and generator and is shown in Figure 3-14. It can be observed that this ratio holds the key to energy arbitrage and the usefulness of BESS units. 


\section{RESULTS}

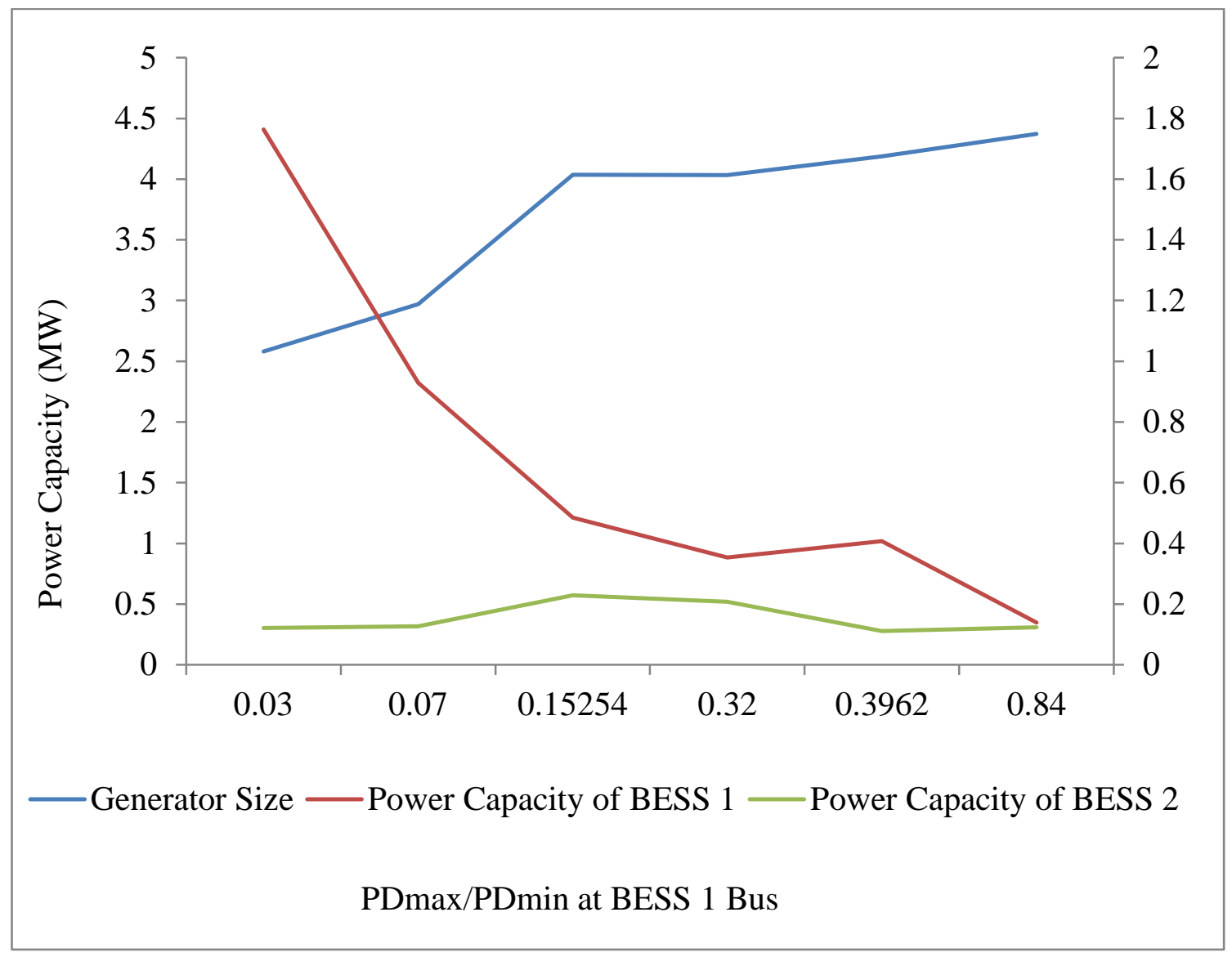

Figure 3-14 BESS and Generator size for different ratio of off-peak to peak load

\subsection{Effect of Life-Cycle-Usage Characteristics}

Considering (2.1) is expanded using (2.12) and (2.13):

$$
\begin{aligned}
& D^{D O D_{k}} \cdot N C_{k} \cdot N Y_{k}=\text { EConst }_{k} \\
& \frac{\left[\max \left(E E_{k h}\right)-\min \left(E E_{k h}\right)\right]}{\overline{E E}_{k}} \cdot \frac{\sum_{h=1}^{N H}\left|P E_{k h}\right|}{2 \overline{E E}_{k}} \cdot N Y_{k}=\text { EConst }_{k}
\end{aligned}
$$

On reviewing (3.2), certain aspects of sizing BESS units can be understood. The first term represents depth of discharge. The second term represents number of cycles. For a given usage, energy usage in the first term and power usage in the numerator of the second term, leaves the ratio of number of years $\left(N Y_{k}\right)$ and the square of energy capacity 


\section{RESULTS}

$\left(\overline{E E}_{k}\right)$. On inspecting this relationship, a larger energy capacity enables a higher number of years whereby the annualized capital costs is reduced. The proposed formulation optimizes this nonlinear relationship and minimizes the cost of asset planning.

In Figure 3-15, all BESS parameters have been kept constant except NY and energy capacity; the relationship between energy capacity of BESS and total energy cost can be seen. As expected, increasing the energy capacity results in an increased NY and reduced total energy asset costs.

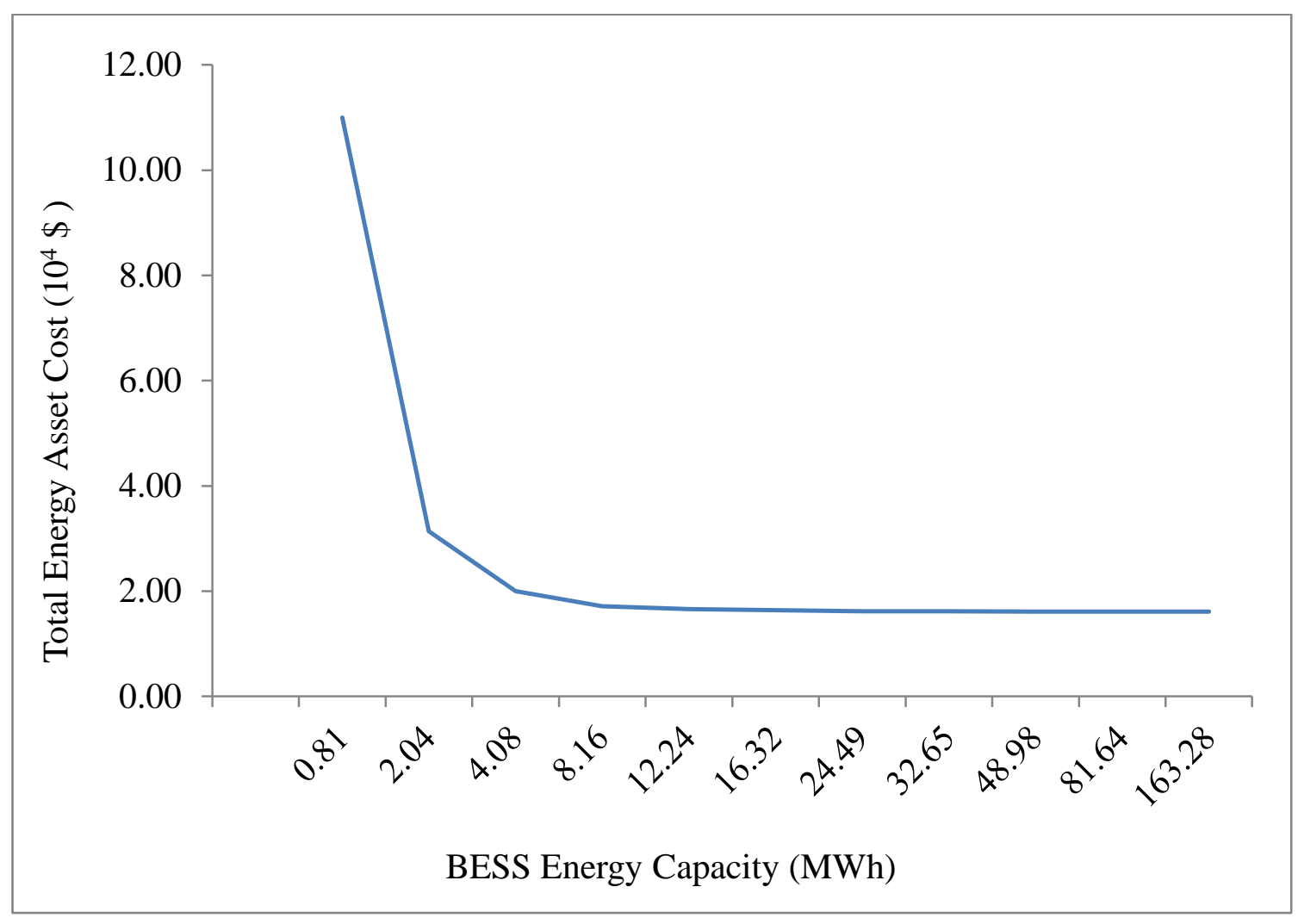

Figure 3-15 Energy Capacity vs. energy cost in 6-bus system 


\section{RESULTS}

\subsection{Chapter Summary}

In this chapter, the two test systems used have been explained and their characteristics are discussed. After solving the asset expansion problem for these two test systems, the respective voltage phasors as well as BESS and generator energy and power are shown. Energy costs and resulting asset sizing for each test system are compared in the systems with and without the BESS and it was shown that utilizing the BESS can reduce the annualized system cost and generator size.

Each of the test systems have then been modified in terms of off-peak to peak load ratio to study how this ratio will affect battery sizing and costs. The results for the two cases of sensitivity analysis have been shown in this chapter as well. It is shown that with constant peak load, increasing the minimum load results in larger sized generators while decreasing the BESS size.

To the best of author's knowledge, the obtained results are the first in the literature to study optimal asset planning investment for a distribution system while taking the BESS life, depth of discharge and number of cycles into consideration. 


\section{CHAPTER 4}

\section{Conclusions}

\subsection{Summary and contribution}

Asset planning is an integral and important function in an electric distribution company. Importance of accurate equipment and asset modeling in consideration for asset expansion planning cannot be understated. Traditional asset expansion planning considered conventional equipment such as transformers, generators, switchgear, etc. Recent research works have proposed the use of energy storage systems such as BESS. However, BESS has highly nonlinear characteristics unlike typical electromechanical systems used in distribution systems hitherto.

In this thesis, a novel asset expansion planning work is undertaken wherein nonlinear characteristics of BESS that interlinks asset life in years to usage parameters such as number of storage cycles per day and depth of discharge is considered in detail. This relation is then included in a typical expansion planning.

The set of linear and non-linear constraints explained in chapter 2 have been used to solve the optimal asset expansion problem which results in minimizing the cost and optimizing the BESS size.

The method is then evaluated in a synthetic 6-bus system and an IEEE 33-bus distribution system. Optimal results size the BESS units such that net asset costs for expansion are minimized. In addition, a sensitivity analysis is completed wherein, we show that off-peak to peak load ratio is a key parameter that controls energy arbitrage opportunity and thus there exists a potential for optimally sizing BESS units. For example, in the 6-bus test system, the total energy cost has gone down from $\$ 35,470$ to $\$ 17,100$ due to the addition of the optimized BESS. 


\section{CONCLUSIONS}

In chapter 1, the application of energy storage systems and its many types have been explained. Reasons for choosing Lithium-ion battery as the main type of energy storage in this study are listed as well. Previous work done in the area of energy storage systems application in power systems are summarized in this chapter as well. In chapter 2, the problem has been outlined and solution method has been explained. In chapter 3 , the test systems and data sets used in order to solve the problem have been characterized and explained. The results found for each test system through the solution method have also been explained in this chapter. The effects of peak load on BESS and generator size and cost have been studied through a sensitivity analysis as well.

\subsection{Future Work}

In this work, BESS locations were automatically chosen to be at buses with highest load peaks. In future works, this algorithm may be combined with BESS optimal location algorithm to prove if it is indeed logical to install BESS at such sites and if not, to find the optimum location.

Also, the algorithm used in this work may be used in transmission upgrade deferral projects to determine the benefits of using energy storage to defer the necessary system upgrade. In which case, the problem becomes a nonlinear mixed-integer problem and would require more robust solvers. 


\section{APPENDICES}

In this section the test systems data have been presented. The components of each system as well as their line impedances have been shown in the tables as well. For the 33-bus test system, the resulting voltages for each bus and in each time zone are shown in table 5-7 and 5-8. Tables 5-4, 5-5 and 5-6 show the load data for the two systems in each time zone.

Table 5-1 6-Bus system characteristics

\begin{tabular}{|l|c|}
\hline No. of Generators & 1 \\
\hline No. of Buses & 6 \\
\hline No. of Load Buses & 5 \\
\hline No. of Batteries & 1 \\
\hline No. of Transformers & 0 \\
\hline No. of Capacitors & 0 \\
\hline No. of Transmission Lines & 5 \\
\hline
\end{tabular}

Table 5-2 33-Bus system characteristics

\begin{tabular}{|l|c|}
\hline No. of Generators & 1 \\
\hline No. of Buses & 33 \\
\hline No. of Load Buses & 32 \\
\hline No. of Batteries & 2 \\
\hline No. of Transformers & 0 \\
\hline No. of Capacitors & 0 \\
\hline No. of Transmission Lines & 32 \\
\hline
\end{tabular}


Table 5-3 6-Bus system line impedance values

\begin{tabular}{|c|c|c|c|}
\hline From Bus & To Bus & $\mathrm{R}(\mathrm{PU})$ & $\mathrm{X}(\mathrm{PU})$ \\
\hline 1 & 2 & 0.0001 & 0 \\
\hline 2 & 3 & 0.0005 & 0.0003 \\
\hline 3 & 4 & 0.0004 & 0.0002 \\
\hline 4 & 5 & 0.0004 & 0.0002 \\
\hline 5 & 6 & 0.0008 & 0.0007 \\
\hline
\end{tabular}

Table 5-4 6-Bus system real power load values

\begin{tabular}{|c|c|c|c|}
\hline Bus No. & Time Zone 1 & Time zone 2 & Time Zone 3 \\
\hline \multicolumn{4}{|c|}{ PD (MW) } \\
\hline 2 & 0.3 & 0.9 & 1.5 \\
\hline 3 & 0.4 & 11.2 & 2 \\
\hline 4 & 0.24 & 0.72 & 1.2 \\
\hline 5 & 0.4 & 1.2 & 2 \\
\hline 6 & 0.22 & 0.66 & 1.1 \\
\hline \multicolumn{4}{|c|}{ QD (MVAR) } \\
\hline 2 & 0.12 & 0.36 & 0.6 \\
\hline 3 & 0.04 & 1.12 & 0.2 \\
\hline 4 & 0.12 & 0.36 & 0.6 \\
\hline 5 & 0.06 & 0.18 & 0.3 \\
\hline 6 & 0.08 & 0.24 & 0.4 \\
\hline
\end{tabular}


Table 5-5 33-Bus system reactive power load values in each time zone

\begin{tabular}{|c|c|c|c|}
\hline \multicolumn{4}{|c|}{ QD(MVAR) } \\
\hline Bus No. & Time Zone 1 & Time Zone 2 & Time Zone 3 \\
\hline 2 & 0.012 & 0.036 & 0.06 \\
\hline 3 & 0.008 & 0.2240 & 0.04 \\
\hline 4 & 0.016 & 0.048 & 0.08 \\
\hline 5 & 0.006 & 0.018 & 0.03 \\
\hline 6 & 0.004 & 0.012 & 0.02 \\
\hline 7 & 0.02 & 0.06 & 0.1 \\
\hline 8 & 0.02 & 0.06 & 0.1 \\
\hline 9 & 0.004 & 0.012 & 0.02 \\
\hline 10 & 0.004 & 0.012 & 0.02 \\
\hline 11 & 0.006 & 0.018 & 0.03 \\
\hline 12 & 0.007 & 0.021 & 0.035 \\
\hline 13 & 0.007 & 0.021 & 0.035 \\
\hline 14 & 0.016 & 0.048 & 0.08 \\
\hline 15 & 0.002 & 0.056 & 0.01 \\
\hline 16 & 0.004 & 0.012 & 0.02 \\
\hline 17 & 0.004 & 0.012 & 0.02 \\
\hline 18 & 0.008 & 0.024 & 0.04 \\
\hline 19 & 0.008 & 0.024 & 0.04 \\
\hline
\end{tabular}


Table 5-5 Cont'd. 33-Bus system reactive power load values in each time zone

\begin{tabular}{|c|c|c|c|}
\hline \multicolumn{4}{|c|}{$\mathrm{QD}(\mathrm{MVAR})$} \\
\hline Bus No. & Time Zone 1 & Time Zone 2 & Time Zone 3 \\
\hline 20 & 0.008 & 0.024 & 0.04 \\
\hline 21 & 0.008 & 0.024 & 0.04 \\
\hline 22 & 0.008 & 0.024 & 0.04 \\
\hline 23 & 0.01 & 0.03 & 0.05 \\
\hline 24 & 0.04 & 0.12 & 0.2 \\
\hline 25 & 0.04 & 0.12 & 0.2 \\
\hline 26 & 0.005 & 0.015 & 0.025 \\
\hline 27 & 0.005 & 0.015 & 0.025 \\
\hline 28 & 0.004 & 0.012 & 0.02 \\
\hline 29 & 0.014 & 0.042 & 0.07 \\
\hline 30 & 0.12 & 0.36 & 0.6 \\
\hline 31 & 0.014 & 0.042 & 0.07 \\
\hline 32 & 0.02 & 0.06 & 0.1 \\
\hline 33 & 0.008 & 0.024 & 0.04 \\
\hline
\end{tabular}


Table 5-6 33-Bus system real power load values

\begin{tabular}{|c|c|c|c|}
\hline \multicolumn{4}{|c|}{$\mathrm{PD}(\mathrm{MW})$} \\
\hline Bus No. & Time Zone 1 & Time Zone 2 & Time Zone 3 \\
\hline 2 & 0.02 & 0.06 & 0.1 \\
\hline 3 & 0.018 & 0.504 & 0.09 \\
\hline 4 & 0.024 & 0.072 & 0.12 \\
\hline 5 & 0.012 & 0.036 & 0.06 \\
\hline 6 & 0.012 & 0.036 & 0.06 \\
\hline 7 & 0.04 & 0.12 & 0.2 \\
\hline 8 & 0.04 & 0.12 & 0.2 \\
\hline 9 & 0.012 & 0.036 & 0.06 \\
\hline 10 & 0.012 & 0.036 & 0.06 \\
\hline 11 & 0.009 & 0.027 & 0.045 \\
\hline 12 & 0.012 & 0.036 & 0.06 \\
\hline 13 & 0.012 & 0.036 & 0.06 \\
\hline 14 & 0.024 & 0.072 & 0.12 \\
\hline 15 & 0.012 & 0.336 & 0.06 \\
\hline 16 & 0.012 & 0.036 & 0.06 \\
\hline 17 & 0.012 & 0.036 & 0.06 \\
\hline 18 & 0.018 & 0.054 & 0.09 \\
\hline 19 & 0.018 & 0.054 & 0.09 \\
\hline
\end{tabular}


Table 5-6 Cont'd. 33-Bus system real power load values

\begin{tabular}{|c|c|c|c|}
\hline \multicolumn{4}{|c|}{$\mathrm{PD}(\mathrm{MW})$} \\
\hline Bus No. & Time Zone 1 & Time Zone 2 & Time Zone 3 \\
\hline 20 & 0.018 & 0.054 & 0.09 \\
\hline 21 & 0.018 & 0.054 & 0.09 \\
\hline 22 & 0.018 & 0.054 & 0.09 \\
\hline 23 & 0.018 & 0.054 & 0.09 \\
\hline 24 & 0.084 & 0.252 & 0.42 \\
\hline 25 & 0.084 & 0.252 & 0.42 \\
\hline 26 & 0.012 & 0.036 & 0.06 \\
\hline 27 & 0.012 & 0.036 & 0.06 \\
\hline 28 & 0.012 & 0.036 & 0.06 \\
\hline 29 & 0.024 & 0.072 & 0.12 \\
\hline 30 & 0.04 & 0.12 & 0.2 \\
\hline 31 & 0.03 & 0.09 & 0.15 \\
\hline 32 & 0.042 & 0.126 & 0.21 \\
\hline 33 & 0.012 & 0.036 & 0.06 \\
\hline
\end{tabular}


Table 5-7 33-bus system resulting voltage magnitude at each bus in each time zone

\begin{tabular}{|c|c|c|c|}
\hline \multicolumn{4}{|c|}{ Voltage Magnitude (V) } \\
\hline Bus No. & Time Zone 1 & Time Zone 2 & Time Zone 3 \\
\hline 1 & 1 & 1 & 1 \\
\hline 2 & 0.9983 & 0.998 & 0.99775 \\
\hline 3 & 0.9897 & 0.9884 & 0.9878 \\
\hline 4 & 0.9847 & 0.9841 & 0.9826 \\
\hline & 0.9796 & 0.98 & 0.9777 \\
\hline ( & 0.968 & 0.9695 & 0.9647 \\
\hline 7 & 0.9652 & 0.9674 & 0.9624 \\
\hline 0 & 0.9461 & 0.9601 & 0.9596 \\
\hline 0 & 0.935 & 0.9567 & 0.9599 \\
\hline 10 & 0.9239 & 0.9537 & 0.9606 \\
\hline 11 & 0.92198 & 0.9533 & 0.961 \\
\hline 12 & 0.9181 & 0.9526 & 0.9618 \\
\hline & 0.903 & 0.9495 & 0.9648 \\
\hline 14 & 0.8974 & 0.9483 & 0.966 \\
\hline 15 & 0.8916 & 0.9476 & 0.9682 \\
\hline & 0.8913 & 0.9468 & 0.9669 \\
\hline & 0.891 & 0.9456 & 0.965 \\
\hline 18 & 0.8908 & 0.9453 & 0.9644 \\
\hline
\end{tabular}


Table 5-7 Cont'd. 33-bus system resulting voltage magnitude at each bus in each time zone

\begin{tabular}{|c|c|c|c|}
\hline \multicolumn{4}{|c|}{ Voltage Magnitude (V) } \\
\hline Bus No. & Time Zone 1 & Time Zone 2 & Time Zone 3 \\
\hline 19 & 0.9982 & 0.9977 & 0.9972 \\
\hline 20 & 0.9975 & 0.9955 & 0.9936 \\
\hline 21 & 0.9974 & 0.9951 & 0.993 \\
\hline 22 & 0.9972 & 0.9947 & 0.9923 \\
\hline 23 & 0.989 & 0.9862 & 0.9842 \\
\hline 24 & 0.9877 & 0.9823 & 0.9776 \\
\hline 25 & 0.987 & 0.9803 & 0.9743 \\
\hline 26 & 0.9676 & 0.9684 & 0.9628 \\
\hline 27 & 0.9671 & 0.9669 & 0.9603 \\
\hline 28 & 0.9649 & 0.9603 & 0.949 \\
\hline 29 & 0.9634 & 0.9555 & 0.9409 \\
\hline 30 & 0.9627 & 0.9535 & 0.9374 \\
\hline 31 & 0.9619 & 0.9511 & 0.9333 \\
\hline 32 & 0.9617 & 0.9505 & 0.9324 \\
\hline 33 & 0.9617 & 0.9504 & 0.9322 \\
\hline
\end{tabular}


Table 5-8 33-Bus system resulting voltage phasor at each bus in each time zone

\begin{tabular}{|c|c|c|c|}
\hline \multicolumn{4}{|c|}{ Voltage Phase Angle (Rad) } \\
\hline Bus No. & Time Zone 1 & Time Zone 2 & Time Zone 3 \\
\hline 1 & 0 & 0 & 0 \\
\hline 2 & -0.0004 & 0.0002 & 0.0006 \\
\hline 3 & -0.0027 & 0.0013 & 0.0039 \\
\hline 4 & -0.0039 & 0.0022 & 0.0062 \\
\hline 5 & -0.0053 & 0.0031 & 0.0085 \\
\hline 6 & -0.0118 & 0.0028 & 0.0112 \\
\hline 7 & -0.0184 & 0.0009 & 0.0113 \\
\hline 8 & -0.03 & 0.0007 & 0.0166 \\
\hline 9 & -0.0372 & 0.0007 & 0.0201 \\
\hline 10 & -0.0445 & 0.0009 & 0.0238 \\
\hline 11 & -0.04505 & 0.001 & 0.02437 \\
\hline 12 & -0.0461 & 0.0014 & 0.02534 \\
\hline 13 & -0.058 & 0.0016 & 0.0312 \\
\hline 14 & -0.0655 & 0.0015 & 0.0344 \\
\hline 15 & -0.0711 & 0.0016 & 0.0371 \\
\hline 16 & -0.0712 & 0.0014 & 0.0367 \\
\hline 17 & -0.0715 & 0.0007 & 0.0355 \\
\hline 18 & -0.0715 & 0.0006 & 0.0354 \\
\hline
\end{tabular}


Table 5-8 Cont'd. 33-Bus system resulting voltage phasor at each bus in each time zone

\begin{tabular}{|c|c|c|c|}
\hline \multicolumn{4}{|c|}{ Voltage Phase Angle (Rad) } \\
\hline Bus No. & Time Zone 1 & Time Zone 2 & Time Zone 3 \\
\hline 19 & -0.0004 & 0.0 & 0.0004 \\
\hline 20 & -0.0007 & -0.0006 & -0.0007 \\
\hline 21 & -0.0007 & -0.0008 & -0.001 \\
\hline 22 & -0.0008 & -0.001 & -0.0014 \\
\hline 23 & -0.0028 & 0.001 & 0.0034 \\
\hline 24 & -0.003 & 0.0 & 0.0019 \\
\hline 25 & -0.0032 & -0.0003 & 0.0011 \\
\hline 26 & -0.0117 & 0.0032 & 0.012 \\
\hline 27 & -0.0115 & 0.0037 & 0.0129 \\
\hline 28 & -0.0112 & 0.0046 & 0.0143 \\
\hline 29 & -0.011 & 0.0054 & 0.0156 \\
\hline 30 & -0.0106 & 0.0064 & 0.0174 \\
\hline 31 & -0.0108 & 0.0056 & 0.016 \\
\hline 32 & -0.011 & 0.0053 & 0.0156 \\
\hline 33 & -0.011 & 0.0053 & 0.0154 \\
\hline
\end{tabular}


Table 5-9 33-Bus system line impedance values

\begin{tabular}{|c|c|c|c|}
\hline From Bus & To Bus & $\mathrm{R}(\mathrm{PU})$ & $\mathrm{X}(\mathrm{PU})$ \\
\hline 1 & 2 & 0.0922 & 0.047 \\
\hline 2 & 3 & 0.493 & 0.2511 \\
\hline 3 & 4 & 0.366 & 0.1864 \\
\hline 4 & 5 & 0.3811 & 0.1941 \\
\hline 5 & 6 & 0.819 & 0.707 \\
\hline 6 & 7 & 0.1872 & 0.6188 \\
\hline 7 & 8 & 1.7114 & 1.2351 \\
\hline 8 & 9 & 1.03 & 0.74 \\
\hline 9 & 10 & 1.044 & 0.74 \\
\hline 10 & 11 & 0.1966 & 0.065 \\
\hline 11 & 12 & 0.3744 & 0.1238 \\
\hline 12 & 13 & 1.468 & 1.155 \\
\hline 13 & 14 & 0.5416 & 0.7129 \\
\hline 14 & 15 & 0.591 & 0.526 \\
\hline 15 & 16 & 0.7463 & 0.545 \\
\hline 16 & 17 & 1.289 & 1.721 \\
\hline 17 & 18 & 0.732 & 0.574 \\
\hline 18 & 19 & 0.164 & 0.1565 \\
\hline 19 & 20 & 1.5042 & 1.3554 \\
\hline 20 & 21 & 0.4095 & 0.4784 \\
\hline 21 & 22 & 0.7089 & 0.9373 \\
\hline 22 & 23 & 0.4512 & 0.3083 \\
\hline 23 & 24 & 0.898 & 0.7091 \\
\hline 24 & 25 & 0.896 & 0.7011 \\
\hline 25 & 26 & 0.203 & 0.1034 \\
\hline 26 & 27 & 0.2842 & 0.1447 \\
\hline 27 & 28 & 1.059 & 0.9337 \\
\hline 28 & 29 & 0.8042 & 0.7006 \\
\hline
\end{tabular}


Table 5-9 Cont'd. 33-Bus system line impedance values

\begin{tabular}{|c|c|c|c|}
\hline From Bus & To Bus & R (PU) & X(PU) \\
\hline 29 & 30 & 0.5075 & 0.2585 \\
\hline 30 & 31 & 0.9744 & 0.963 \\
\hline 31 & 32 & 0.3105 & 0.3619 \\
\hline 32 & 33 & 0.341 & 0.5302 \\
\hline
\end{tabular}




\section{REFERENCES}

[1] A. A. M. Sayigh, "South-south networking and cooperation on renewable energy and sustainable development," Renewable Energy, vol. 29, pp. 2273-2275, 12// 2004.

[2] N. Zhang, F. Kong, Y. Choi, and P. Zhou, "The effect of size-control policy on unified energy and carbon efficiency for Chinese fossil fuel power plants," Energy Policy, vol. 70, pp. 193-200, 7// 2014.

[3] G. Nicoletti, N. Arcuri, G. Nicoletti, and R. Bruno, "A technical and environmental comparison between hydrogen and some fossil fuels," Energy Conversion and Management, vol. 89, pp. 205-213, 1/1/ 2015.

[4] J. Quanyuan and W. Haijiao, "Two-Time-Scale Coordination Control for a Battery Energy Storage System to Mitigate Wind Power Fluctuations," Energy Conversion, IEEE Transactions on, vol. 28, pp. 52-61, 2013.

[5] R. Ghaffari and B. Venkatesh, "Network constrained model for options based reserve procurement by wind generators using binomial tree," Renewable Energy, vol. 80, pp. 348-358, 8// 2015.

[6] L. Xiangjun, H. Dong, and L. Xiaokang, "Battery Energy Storage Station (BESS)Based Smoothing Control of Photovoltaic (PV) and Wind Power Generation Fluctuations," Sustainable Energy, IEEE Transactions on, vol. 4, pp. 464-473, 2013.

[7] B. Dunn, H. Kamath, and J.-M. Tarascon, "Electrical Energy Storage for the Grid: A Battery of Choices," Science, vol. 334, pp. 928-935, 2011.

[8] Z. Bo, Z. Xuesong, C. Jian, W. Caisheng, and G. Li, "Operation Optimization of Standalone Microgrids Considering Lifetime Characteristics of Battery Energy Storage System," Sustainable Energy, IEEE Transactions on, vol. 4, pp. 934-943, 2013.

[9] A. A. Akhil, G. Huff, A. B. Currier, B. C. Kaun, D. M. Rastler, S. B. Chen, et al., DOE/EPRI 2013 Electricity StorageHandbook in Collaboration with NRECA: Sandia National Labratories, 2013.

[10] G. L. Soloveichik, "Battery technologies for large-scale stationary energy storage," Апnu Rev Chem Biomol Eng, vol. 2, pp. 503-27, 2011.

[11] K. S. Tam and P. Kumar, "Impact of superconductive magnetic energy storage on electric power transmission," Energy Conversion, IEEE Transactions on, vol. 5, pp. 501-511, 1990.

[12] P. Tixador, "Superconducting magnetic energy storage; status and Perspective," in IEEE/CSC\&ESAS European Superconductivity news forum, 2008.

[13] T. M. I. Mahlia, T. J. Saktisahdan, A. Jannifar, M. H. Hasan, and H. S. C. Matseelar, "A review of available methods and development on energy storage; technology update," Renewable and Sustainable Energy Reviews, vol. 33, pp. 532-545, 5// 2014.

[14] S. G. Chalk and J. F. Miller, "Key challenges and recent progress in batteries, fuel cells, and hydrogen storage for clean energy systems," Journal of Power Sources, vol. 159, pp. 73-80, 9/13/ 2006. 
[15] H. V. Venkatasetty and Y. U. Jeong, "Recent advances in lithium-ion and lithiumpolymer batteries," in Battery Conference on Applications and Advances, 2002. The Seventeenth Annual, 2002, pp. 173-178.

[16] M. Daowd, N. Omar, B. Verbrugge, P. V. D. Bossche, and J. V. Mierlo, "Battery Models Parameter Estimation based on MATLAB/Simulink®," presented at the EVS-25, Shenzhen, China, Nov. 2010.

[17] J. Zhang, B. Wu, Z. Li, and J. Huang, "Simultaneous estimation of thermal parameters for large-format laminated lithium-ion batteries," Journal of Power Sources, vol. 259, pp. 106-116, 8/1/ 2014.

[18] Learn About Batteries [Online]. Available: <div data-canvaswidth="415.3406099999999" style="left: 190.1pxAvailable: top: 838.605pxAvailable: font-size: 19.925pxAvailable: ">http://batteryuniversity.com/learn/article/types_of_Lithium_ion

[19] C. Abbey and G. Joos, "Supercapacitor Energy Storage for Wind Energy Applications," Industry Applications, IEEE Transactions on, vol. 43, pp. 769-776, 2007.

[20] C. H. Lo and M. D. Anderson, "Economic dispatch and optimal sizing of battery energy storage systems in utility load-leveling operations," Energy Conversion, IEEE Transactions on, vol. 14, pp. 824-829, 1999.

[21] D. K. Maly and K. S. Kwan, "Optimal battery energy storage system (BESS) charge scheduling with dynamic programming," Science, Measurement and Technology, IEE Proceedings -, vol. 142, pp. 453-458, 1995.

[22] F. A. Chacra, P. Bastard, G. Fleury, and R. Clavreul, "Impact of energy storage costs on economical performance in a distribution substation," Power Systems, IEEE Transactions on, vol. 20, pp. 684-691, 2005.

[23] N. S. Rau and B. Tayor, "A central inventory of storage and other technologies to defer distribution upgrades-optimization and economics," Power Delivery, IEEE Transactions on, vol. 13, pp. 194-202, 1998.

[24] L. Tsung-Ying and C. Nanming, "Optimal capacity of the battery energy storage system in a power system," Energy Conversion, IEEE Transactions on, vol. 8, pp. 667-673, 1993.

[25] A. Oudalov, R. Cherkaoui, and A. Beguin, "Sizing and Optimal Operation of Battery Energy Storage System for Peak Shaving Application," in Power Tech, 2007 IEEE Lausanne, 2007, pp. 621-625.

[26] "IEEE Recommended Practice for Sizing Lead-Acid Batteries for Stationary Applications," IEEE Std 485-2010 (Revision of IEEE Std 485-1997), pp. 1-90, 2011.

[27] O. Ekren and B. Y. Ekren, "Size optimization of a PV/wind hybrid energy conversion system with battery storage using simulated annealing," Applied Energy, vol. 87, pp. 592-598, 2// 2010.

[28] J. Kyung-Hee, K. Hoyong, and R. Daeseok, "Determination of the installation site and optimal capacity of the battery energy storage system for load leveling," Energy Conversion, IEEE Transactions on, vol. 11, pp. 162-167, 1996.

[29] J. T. Alt, M. D. Anderson, and R. G. Jungst, "Assessment of utility side cost savings from battery energy storage," Power Systems, IEEE Transactions on, vol. 12, pp. 1112-1120, 1997. 
[30] A. Oudalov, D. Chartouni, C. Ohler, and G. Linhofer, "Value Analysis of Battery Energy Storage Applications in Power Systems," in Power Systems Conference and Exposition, 2006. PSCE '06. 2006 IEEE PES, 2006, pp. 2206-2211.

[31] L. Tsung-Ying and C. Nanming, "Determination of optimal contract capacities and optimal sizes of battery energy storage systems for time-of-use rates industrial customers," Energy Conversion, IEEE Transactions on, vol. 10, pp. 562-568, 1995.

[32] S. X. Chen and H. B. Gooi, "Jump and Shift Method for Multi-Objective Optimization," Industrial Electronics, IEEE Transactions on, vol. 58, pp. 45384548, 2011.

[33] C. Chen, S. Duan, T. Cai, B. Liu, and G. Hu, "Smart energy management system for optimal microgrid economic operation," Renewable Power Generation, IET, vol. 5, pp. 258-267, 2011.

[34] H. Morais, P. Kádár, P. Faria, Z. A. Vale, and H. M. Khodr, "Optimal scheduling of a renewable micro-grid in an isolated load area using mixed-integer linear programming," Renewable Energy, vol. 35, pp. 151-156, 1// 2010.

[35] J. D. Maclay, J. Brouwer, and G. S. Samuelsen, "Dynamic modeling of hybrid energy storage systems coupled to photovoltaic generation in residential applications," Journal of Power Sources, vol. 163, pp. 916-925, 1/1/ 2007.

[36] S. R. Vosen and J. O. Keller, "Hybrid energy storage systems for stand-alone electric power systems: optimization of system performance and cost through control strategies1," International Journal of Hydrogen Energy, vol. 24, pp. 11391156, 12// 1999.

[37] C.-H. Li, X.-J. Zhu, G.-Y. Cao, S. Sui, and M.-R. Hu, "Dynamic modeling and sizing optimization of stand-alone photovoltaic power systems using hybrid energy storage technology," Renewable Energy, vol. 34, pp. 815-826, 3// 2009.

[38] S. Wei-Fu, H. Shyh-Jier, and E. L. Chin, "Economic analysis for demand-side hybrid photovoltaic and battery energy storage system," Industry Applications, IEEE Transactions on, vol. 37, pp. 171-177, 2001.

[39] F. S. Garcia, A. A. Ferreira, and J. A. Pomilio, "Control Strategy for BatteryUltracapacitor Hybrid Energy Storage System," in Applied Power Electronics Conference and Exposition, 2009. APEC 2009. Twenty-Fourth Annual IEEE, 2009, pp. 826-832.

[40] J. Garche and A. Jossen, "Battery management systems (BMS) for increasing battery life time," in Telecommunications Energy Special Conference, 2000. TELESCON 2000. The Third International, 2000, pp. 81-88.

[41] I. Duggal and B. Venkatesh, "Short-Term Scheduling of Thermal Generators and Battery Storage With Depth of Discharge-Based Cost Model," Power Systems, IEEE Transactions on, vol. 30, pp. 2110-2118, 2015.

[42] H. L. Willis, power distribution planning reference book, second ed.: CRC Press, 2004.

[43] P. A. Jensen and J. F. Bard, Operations research models and methods: John Wiley \& Sons Incorporated, 2003. 